\title{
Quantitative and qualitative ${ }^{1} \mathrm{H},{ }^{13} \mathrm{C}$, and ${ }^{15} \mathrm{~N}$ NMR spectroscopic investigation of the
}

\section{urea-formaldehyde resin synthesis}

\author{
Oliver Steinhof, ${ }^{* \dagger}$ Eléonore J. Kibrik, ${ }^{\ddagger}$ Günter Scherr, ${ }^{\mathbb{I}}$ and Hans Hasse ${ }^{\ddagger}$ \\ Institute of Thermodynamics and Thermal Process Engineering, Universität Stuttgart, 70569 \\ Stuttgart, Germany, Laboratory of Engineering Thermodynamics, University of Kaiserslautern, \\ 67663 Kaiserslautern, Germany, and BASF SE, 67056 Ludwigshafen, Germany. \\ E-mail: steinhof@itt.uni-stuttgart.de
}

\begin{abstract}
Urea-formaldehyde resins are bulk products of the chemical industry. Their synthesis involves a complex reaction network. The present work contributes to its elucidation by presenting results from detailed NMR spectroscopic studies with different methods. Besides ${ }^{1} \mathrm{H}$ NMR and ${ }^{13} \mathrm{C}$ NMR also ${ }^{15} \mathrm{~N}$ NMR spectroscopy is applied. ${ }^{15} \mathrm{~N}$-enriched urea was used for the investigations. A detailed NMR signal assignment and a model of the reaction network of the hydroxymethylation step of the synthesis are presented. Due to its higher spectral dispersion and the fact, that all key reactions directly involve the nitrogen centers, ${ }^{15} \mathrm{~N}$ NMR provides a much larger amount of detail than ${ }^{1} \mathrm{H}$ and ${ }^{13} \mathrm{C}$ NMR spectroscopy. Symmetric and asymmetric dimethylol urea can be clearly distinguished and separated from monomethylol

\footnotetext{
${ }^{*}$ To whom correspondence should be addressed

${ }^{\dagger}$ Institute of Thermodynamics and Thermal Process Engineering, Universität Stuttgart, 70569 Stuttgart, Germany

${ }^{+}$Laboratory of Engineering Thermodynamics, University of Kaiserslautern, 67663 Kaiserslautern, Germany

"BASF SE, 67056 Ludwigshafen, Germany.
} 
urea, trimethylol urea and methylene bridged urea. The existence of hemiformals of methylol ureas is confirmed. 1,3,5-oxadiazinan-4-on (uron) and its derivatives were not found in the reaction mixtures investigated here, but were prepared via alternative routes. The molar ratios of formaldehyde to urea were 1,2 and 4, the $\mathrm{pH}$-values 7.5 and 8.5 and the reaction temperature $60^{\circ} \mathrm{C}$.

\section{Introduction}

Urea-formaldehyde resins are used as binders for wood products. The annual world-wide production was about $9.2 \cdot 10^{6}$ tons in $2003^{1}$ and rose to $14.2 \cdot 10^{6}$ tons in $2006^{2}$. These resins are usually prepared in large-scale batch processes involving a $\mathrm{pH}$-value step change. During the first phase, formaldehyde adds to urea under mildly alkaline conditions to form hydroxymethylated ureas ${ }^{3}$. In the second phase, these intermediates condensate under acidic conditions to form methylene- and methoxymethylene bridged ureas. The foundations to the understanding of this complex reaction network have been laid out by Kadowaki ${ }^{4}$. Later, Smythe ${ }^{5-7}$, Crowe and Lynch ${ }^{8,9}$, de Jong and de Jonge ${ }^{10-18}$, Landqvist ${ }^{19-28}$ and Kveton ${ }^{29}$ reported on reaction pathways, reaction mechanisms and reaction kinetics of the main components. Up to now, industrial processes for the production of urea-formaldehyde resins are typically controlled by temperature and $\mathrm{pH}$-value. The degree of condensation is determined by macroscopic properties of the resin, usually viscosity or miscibility with water. There is practical knowledge available that enables relating these control parameters to product quality parameters like adhesiveness and activity. However, the molecular mechanisms responsible for the final properties of the product are not yet fully understood. The optimization of secondary performance properties of the urea-formaldehyde resin like shelf life, hydrolytic stability and formaldehyde emission ${ }^{3}$ while keeping the above mentioned primary properties in the optimal range poses an additional challenge. Furthermore, low emission of formaldehyde from wood products is important. Significant reductions have been achieved ${ }^{30}$, but the final goal of zero formaldehyde emission still lies ahead. The urea-formaldehyde reaction system is complex. This is due to the polydentate nature of urea as related to formaldehyde. The number of possible inter- 
mediates grows exponentially with the conversion rate after urea and formaldehyde are combined (see Section 2). Further complexity arises from the formaldehyde-water reaction system ${ }^{31-33}$, (see Figure 1), which is interconnected to the urea-formaldehyde system via monomeric formaldehyde, being the reactive species in both systems. All reactions in the combined system are equilibrium reactions with rate constants varying by orders of magnitude. To gain analytical insight into the UF-system, a non-invasive analytical technique is needed. NMR-spectroscopy was chosen for the present study due to the wealth in structural information it provides, the possibility to quantify components directly and the simplicity of the experimental setup. Combining ${ }^{1} \mathrm{H},{ }^{13} \mathrm{C}$ and ${ }^{15} \mathrm{~N}$ NMR spectroscopy with ${ }^{15} \mathrm{~N}$-enriched urea as starting material proved to be particularly useful. Already the earliest NMR-spectroscopic investigations of the urea-formaldehyde system by Kambanis and Chiavarini reported on quantitative analysis with ${ }^{1} \mathrm{H}$ NMR spectroscopy ${ }^{34,35}$. Other early analyses of the system by ${ }^{13} \mathrm{C}$ NMR spectroscopy provide qualitative information only ${ }^{36-38}$. Tomita ${ }^{39}$ reported the first quantitative analysis of finished resins by ${ }^{13} \mathrm{C}$ NMR spectroscopy, followed by Rammon et. al. ${ }^{40}$ and $\mathrm{Kim}^{41}$. Christjanson and Siimer combined ${ }^{13} \mathrm{C}$ NMR spectroscopy with thermal analysis ${ }^{42,43}$. Recently Despres et. al. ${ }^{44}$ combined ${ }^{13} \mathrm{C}$ NMR spectroscopy with MALDITOF to provide a detailed analysis of urea-formaldehyde and melamine-urea-formaldehyde resins. ${ }^{15} \mathrm{~N}$ NMR spectroscopy was first used by Ebdon et. al. ${ }^{45,46}$ to characterize urea-formaldehyde intermediates as well as freeze-dried resins, relying on ${ }^{15} \mathrm{~N}$ in natural abundance. Acquisition times of several days were required to achieve an acceptable signal to noise ratio. Thomson ${ }^{47}$ applied ${ }^{15} \mathrm{~N}$ DEPT NMR spectroscopy to investigate the curing process of UF resins. The most recent work in this area has been reported by Angelatos ${ }^{48}$ and Philbrook et. al. ${ }^{49}$, who both used ${ }^{15} \mathrm{~N}$ NMR correlation spectroscopy to identify possible copolymers between urea and melamine in melamineurea-formaldehyde resins. Steinhof studied the urea-formaldehyde system with a combination of 1D and 2D NMR spectroscopy of ${ }^{1} \mathrm{H},{ }^{13} \mathrm{C}$ and ${ }^{15} \mathrm{~N}$ while making use of isotope enriched urea ${ }^{50}$. In the present work, ${ }^{15} \mathrm{~N}$ NMR spectroscopy was used to study the urea-formaldehyde system not only qualitatively, but quantitatively. Furthermore, for the first time ${ }^{15} \mathrm{~N}$-enriched urea was used to study this system. In combination with the results from other NMR spectroscopic methods 
this gives a particularly rich and detailed picture of the complex chemistry of the studied system. The main parameters of the production process of urea-formaldehyde resins are: 1) molar ratio formaldehyde/urea in the feed mixture (FA/U-ratio), 2) water content of the feed mixture (specified here by the overall mass fraction of formaldehyde in the aqueous formaldehyde solution used to prepare the feed mixture), 3) temperature and 4) $\mathrm{pH}$-value. Both temperature and $\mathrm{pH}$-value can be changed during the production process. Also time dependent addition of reactants can be applied. It is not trivial to optimize a process of this kind with regard to a complex set of goals as discussed above. The present study was carried out in ranges of the parameters 1) - 4) which cover industrially relevant conditions ${ }^{51}$. The formaldehyde-urea ratio (FA/U-ratio) was studied at 1, 2 and 4 using an aqueous formaldehyde solution with a formaldehyde concentration of $0.3 \mathrm{~g} / \mathrm{g}$. This concentration was chosen, because it is the highest one that can still be handled at ambient temperature without formation of precipitates. These experiments were carried out at $\mathrm{pH}$-values of 7.5 and 8.5 , all at a temperature of $60^{\circ} \mathrm{C}$. While this temperature is lower than the temperatures encountered in most industrial UF-resin processes, the observed line shapes in the NMR spectra are still sufficiently narrow to allow for acceptable peak assignment and quantitative analysis. It is not expected that the $\mathrm{pH}$-value has an influence on the equilibria of the individual reactions. However, it was found valuable to verify this influence.

\section{Chemical reaction system}

\subsection{Chemistry of the formaldehyde water system}

Formaldehyde is a gas at ambient conditions and commonly used as liquid, aqueous solutions. These solutions are highly reactive multicomponent mixtures ${ }^{31}$. In aqueous solutions, formaldehyde is mainly present as poly(oxymethylene)glycols or $\mathrm{MG}_{n}$ (see Figure 1). The amount of monomeric formaldehyde $\mathrm{CH}_{2} \mathrm{O}$ is very low in these solutions and is expected to be below $1 \cdot 10^{-3}$ $\mathrm{mol} / \mathrm{mol}$ for the conditions studied in the present work ${ }^{52,53}$. Hence, formaldehyde is predominantly present as methylene glycol $\mathrm{MG}_{1}$ and its oligomers $\mathrm{MG}_{n}$. The average chain length of 
the oligomers increases with increasing overall formaldehyde concentration. The reaction equilibria are only slightly temperature-dependent. These reactions occur in all aqueous formaldehyde solutions and are subject to both acid and base catalysis. As formaldehyde is an important base

chemical, these reactions have extensively been studied, see Hahnenstein et al. ${ }^{33,54,55}$, Dahn and Pechy ${ }^{56}$, Maiwald et al. ${ }^{57,58}$, Kuhnert ${ }^{59}$ and the references therein. Both the equilibrium constants and reaction rates are well known. There are several possible side reactions in the formaldehydewater system of which the Cannizzaro reaction, yielding formic acid and methanol, is the most important (see Section 2.3) ${ }^{60,61}$. Remaining from the production process and added as a stabilizer, aqueous formaldehyde solutions often also contain methanol. With methanol, formaldehyde forms the hemiformals of the oligomeric polyoxymethylene glycols. It exhibits a reaction scheme which is similar to that with water. As the formaldehyde solutions used in the present study contained only very small amounts of methanol, the reactions of formaldehyde with methanol play no role in the present study. Abundant data on the equilibria and kinetics of these reactions has been reported elsewhere; see Ott et al. ${ }^{62}$ and the references therein.

\subsection{Main reactions in the urea-formaldehyde system}

The four basic reactions defining the chemistry of urea-formaldehyde resins are described below:

1. Addition offormaldehyde to urea, leading to monomethylol urea. Formaldehyde can also add to the remaining amide protons of monomethylol urea, leading to dimethylol- and trimethylol urea (see Figure 2). Substitution of all four amide protons has never been reported. This reaction follows general acid-base catalysis 63 . In industrial application, this conversion is carried out at a pH-value between 7 and 9.

2. Formation of hemiformals of hydroxymethyl groups. Formaldehyde adds to existing hydroxymethyl groups to form oligomeric hemiformals (see Figure 3). This reaction is similar to the formation of methyleneglycols in the formaldehyde water system.

3. Condensation of methylol ureas with urea and other intermediates possessing amide protons, 
leading to methylene-bridged urea derivatives (see Figure 4). This reaction follows general acid catalysis. In most industrial processes, this is done at $\mathrm{pH}$-value 4-6. However, the reaction also proceeds at lower rates at $\mathrm{pH}$-values exceeding 6 , as was shown in this work.

4. Condensation of hydroxymethyl hemiformals with urea or hydroxymethylated urea forming methoxymethylene or 'ether' bridges, see Figure 5. Recently Kibrik et. al. ${ }^{64,65}$ provided evidence that these intermediates do exist in urea-formaldehyde reaction mixtures. Literature is ambiguous whether the formation of these components is favored under basic conditions during hydroxymethylation ${ }^{11,66-71}$ or under neutral to acidic conditions during condensation and curing ${ }^{29,72-76}$. In this work, methoxymethylene bridges were not taken into account. The peak assignment was completed with the intermediates listed in Table 1.

Urea entities can connect via formation of methylene bridges and likely via methoxymethylene bridges. Due to the fact that one urea unit can form at least three of these bridges, a polymer with a three dimensional network is formed during condensation in the final product. Starting with urea and formaldehyde, the number of possible intermediates grows exponentially while the conversion proceeds. All reactions are reversible, the presence of water provided. An overview of the reaction pathways in the UF reaction system is depicted in Figure 6. All pathways shown were confirmed during the course of this work except for methoxymethylene bridged diureas. Although strong indications suggest their existence ${ }^{64,65}$, literature does not report isolation or characterization of specific examples of these intermediates. The main pathway, temporary intermediates and selected side reactions are indicated.

\subsection{Side reactions in the urea-formaldehyde system}

Intramolecular condensation of symmetric dimethylol urea and its derivatives leads to cyclic structures of the uron type. Isolation and identification of these structures in urea-formaldehyde resins have been reported early by Kadowaki ${ }^{4}$. Their formation was reported to take place under both alkaline and acidic conditions. From that observation it could be concluded, that these species 
form not only during condensation, but also during the hydroxymethylation step under basic conditions ${ }^{75,77,78}$. In the present study, formation of these cyclic structures during hydroxymethylation under conditions similar to the industrial process could not be confirmed. However, uron structures were prepared via alternative pathways and were characterized successfully. Under acidic conditions methanol and other alcohols are converted to ethers. In case of methanol, methoxymethylene ethers are formed from hydroxymethyl groups. This reduces the potential of the resin to form crosslinks due to blockage of required functional groups. This results in a reduced activity of the resin, which is synonymous with lower product quality ${ }^{3}$. Hence, formaldehyde solutions with low methanol content are preferred as feed material for commercial production. Dissociation of urea leads to the formation of ammonia ${ }^{79}$, which reacts with formaldehyde to urotropine. Due to the slow dissociation rate of urea compared to the hydroxymethylation reaction under the studied conditions, only traces of this component were identified in the present study ${ }^{50}$.

\section{Experiments}

\subsection{Approach}

A stepwise approach was taken towards peak assignment. At first, selected intermediates were synthesized and characterized by ${ }^{1} \mathrm{H},{ }^{13} \mathrm{C}$ and ${ }^{15} \mathrm{~N}$ NMR spectroscopy to establish a basic peak assignment. Table 1 lists the components which were prepared and characterized for this purpose. Details on their preparation are described in Section 3.5. In a second step, mixtures of urea and formaldehyde were prepared with ${ }^{15} \mathrm{~N}$-enriched urea (see Section 3.4 ) and analyzed by one-dimensional, directly detected ${ }^{1} \mathrm{H},{ }^{13} \mathrm{C}$ and ${ }^{15} \mathrm{~N}$ NMR spectroscopy (see Sections 3.3 and 4.1). Directly detected, one dimensional NMR spectroscopy was chosen here for its speed and robustness. It is capable to detect tertiary nitrogen and carbon centers directly while maintaining good resolution and minimal artifacts. Table 2 lists the composition and the experimental conditions

of the analyzed reaction mixtures. In a third step, the ${ }^{15} \mathrm{~N}$, and ${ }^{13} \mathrm{C}$ NMR spectra of the reaction mixtures were analyzed qualitatively to refine signal assignment (see Sections 4.3, 4.4 and 4.5). 
Comparing the spectra of mixtures of different FA/U-ratios at different $\mathrm{pH}$-values proved to be essential for peak assignment. As a fourth step this was followed by quantitative analysis (see Sections 4.7 and 4.8). Selected samples were also studied by 2D NMR spectroscopy.

\subsection{Materials}

Urea in prills of $\geq 99 \%$ purity was supplied by BASF SE (Ludwigshafen, Germany). ${ }^{15} \mathrm{~N}$-labeled urea, enriched to $98 \%$ in ${ }^{15} \mathrm{~N}$, was purchased from Deutero GmbH (Kastellaun, Germany). Both materials were used without further purification. Aqueous formaldehyde solution with a formaldehyde mass fraction of $0.3 \mathrm{~g} / \mathrm{g}$ and a methanol mass fraction of less than $0.01 \mathrm{~g} / \mathrm{g}$ was supplied by BASF SE (Ludwigshafen, Germany). Before use, the formaldehyde concentration was determined titrimetrically. The $\mathrm{pH}$-value was adjusted with an aqueous solution of sodium hydroxide $(0.1 \mathrm{~g} / \mathrm{g})$ directly before use. Aqueous phosphate buffer of the concentration of $1 \mathrm{~mol} / \mathrm{l}$ or $0.1 \mathrm{~mol} / \mathrm{l}$ was added as required. All other reagents and solvents were obtained from commercial sources with a minimum purity of $99 \%$ and used without further purification.

\subsection{NMR spectroscopy}

All spectra were recorded on a Varian Unity Inova 400 spectrometer (Varian, Palo Alto, USA) with a field strength of $9.4 \mathrm{~T}$. As all measurements were conducted in aqueous solution, the chemical shifts of ${ }^{1} \mathrm{H}$ and ${ }^{13} \mathrm{C}$ were referenced to the water soluble internal standard 2,2-dimethyl-2silapentan-5-sulfonic acid sodium salt $\left(\mathrm{CH}_{3}\right)_{3} \mathrm{Si}\left(\mathrm{CH}_{2}\right)_{3} \mathrm{SO}_{3} \mathrm{Na}(\mathrm{DSS})^{80}$. For the one-dimensional spectra simple $1 \mathrm{D}$ experiments were used. Both the ${ }^{15} \mathrm{~N}$ and the ${ }^{13} \mathrm{C}$ pulse sequences supported decoupling. For each ${ }^{1} \mathrm{H}$ NMR spectrum only one transient was recorded. The chemical shifts in the ${ }^{15} \mathrm{~N}$-domain were referenced to $\mathrm{CH}_{3} \mathrm{NO}_{2}$, which was used as an external standard. Due to sensitivity and solubility issues ${ }^{15} \mathrm{NH}_{4}{ }^{15} \mathrm{NO}_{3}$ was added as an internal secondary standard to the mixtures (the resonance of ${ }^{15} \mathrm{NO}_{3}$ was used as a reference). The acquisition parameters for 1D${ }^{15} \mathrm{~N}$ NMR spectra were chosen with regard to the longitudinal relaxation times $T_{1}$ of the nitrogen centers. The $T_{1}$ times for the $\mathrm{NH}_{2}$ and $\mathrm{NHR}$ groups $\left(\mathrm{R}=\mathrm{CH}_{2}-\mathrm{OH}, \mathrm{CH}_{2} \mathrm{X}\right)$ were found to be in 
the range of $1-5 \mathrm{~s}$ using standard experiments ${ }^{81}$. For the tertiary $\mathrm{NR}_{2}$ groups, $T_{1}$ was found to be between $28-54 \mathrm{~s}$. The pulse angle was set to $45^{\circ}$, where complete relaxation has taken place after $0.5 \cdot T_{1}{ }^{81}$. The time between scans was set to $60 \mathrm{~s}$. Hence even the tertiary nitrogen centers relax almost completely. See Malz ${ }^{82,83}$ and Maiwald ${ }^{84-86}$ for further information on quantitative NMR spectroscopy. Inverse gated proton decoupling was applied to achieve sufficient signal-to-noise ratio. Acquisition time was $3 \mathrm{~s}$ and the spectral window was $25 \mathrm{kHz}$. The data was acquired at a digital resolution of $0.16 \mathrm{~Hz}$ per data point. Five transients were recorded at a FA/U-ratio of 1 , while nine transients were recorded at FA/U-ratios of 2 and 4 for sensitivity reasons. So the total acquisition time for a $1 \mathrm{D}-{ }^{15} \mathrm{~N}$ NMR spectrum amounted to $5-10 \mathrm{~min}$. For the ${ }^{13} \mathrm{C}$-spectra 64 or 128 transients were recorded at a pulse angle of $56.8^{\circ}$ with 15 s relaxation time and inverse-gated proton decoupling. All ${ }^{13} \mathrm{C}$ shifts reported here are corrected by $-2.66 \mathrm{ppm}$ to be in line with shifts referenced to $\mathrm{TMS}^{87}$. The applied ${ }^{15} \mathrm{~N}$ pulse sequence additionally supported a virtual reference signal (VR), which was used in this study to relate signal integrals to actual analyte concentrations in the sample. The method was pioneered by Mahon ${ }^{88}$ and is also known as ERETIC ${ }^{86,89,90}$. A synthetic FID is generated by the NMR console via an additional channel and injected into the probe during acquisiton. The TTL signal from the console was attenuated by $75 \mathrm{~dB}$ using manual step attenuators. The resulting synthetic signal is referenced to a solution of a standard component of known concentration. Later, the signal can be used as a reference to quantify analyte signals in other samples. The technique relies on the excellent stability of modern spectrometers. Hence it is important that all instrument parameters remain unchanged between the analysis of the reference sample and the sample in question. In this study, the VR was referenced against an aqueous solution of ${ }^{15} \mathrm{~N}$-enriched urea of known concentration. It was used here to determine the actual molar amounts of urea formaldehyde intermediates in the reaction mixtures. This information was used also to determine the recovery rate of urea in these reaction mixtures (see Supplementary Material). VR was applied to ${ }^{15} \mathrm{~N}$ NMR spectroscopy only. 


\subsection{Sample preparation and analysis}

The same procedure was used for all samples. All experiments were conducted directly in standard $5 \mathrm{~mm}$ NMR-tubes. Table 2 gives an overview of the samples studied. First, solid urea was dissolved in phosphate buffer of the required $\mathrm{pH}$-value in the NMR-tube. Then the secondary reference standard ${ }^{15} \mathrm{NH}_{4}{ }^{15} \mathrm{NO}_{3}\left({ }^{15} \mathrm{~N}\right.$ in $99 \%$ abundance, $0.01 \mathrm{~g} / \mathrm{g}$ with regard to urea) was added, followed by the aqueous formaldehyde solution $(0.3 \mathrm{~g} / \mathrm{g})$. Directly before use, the $\mathrm{pH}$-value of the formaldehyde solution was adjusted using an aqueous solution of sodium hydroxide. The sample was mixed and equilibrated for 45 minutes in a thermal bath of $60^{\circ} \mathrm{C}$ before being transferred to the NMR spectrometer. The variation in FA/U-ratio was achieved by changing the quantities of formaldehyde and urea. Phosphate buffer was used to stabilize the $\mathrm{pH}$-value and to maintain a sufficient and uniform fill level of the NMR-tubes. Hence, the water concentration was not controlled, water was always present in large excess. The buffer solution had a buffer salt concentration of 1 $\mathrm{mol} / \mathrm{l}$ for all samples except for Sample 5, where it was $0.1 \mathrm{~mol} / \mathrm{l}$. Sample 5 is identical to Sample 4 except for the lower concentration of the buffer solution used. The intention was to assess the influence of the buffer concentration on the sample composition. In the NMR spectrometer the sample was maintained at $60^{\circ} \mathrm{C}$ during acquisition. $\mathrm{A}^{1} \mathrm{H}$ NMR spectrum was acquired, followed by ${ }^{15} \mathrm{~N}$, ${ }^{13} \mathrm{C}$ and in some cases 2D-NMR spectroscopy. Note that spectra were acquired after the reaction mixtures had reached equilibrium with regard to the hydroxymethylation reactions and to hemiformal formation (see Figures 2 and 3). No equilibrium is attained with regard to the condensation reactions (see Figure 4). Under the reaction conditions investigated here the reaction rates of the condensation reactions are distinctly smaller than 1) the reaction rates of the hydroxymethylation reaction, 2) the formation of hemiformals ${ }^{33,50,53}$ and 3) the time required for analysis of the reaction mixture. Hence, the condition of the reaction mixture is considered to be static during analysis after the hydroxymethylation and the formation of hemiformals virtually reached equilibrium. To control for a possible influence of condensation reactions samples were prepared and analyzed at $\mathrm{pH}$-values of 7.5 and 8.5. Although literature reports the rate of condensation in urea-formaldehyde mixture to be negligible under neutral or basic conditions (see Section 2.2), an increased fraction 
of condensation products was detected in samples prepared at a $\mathrm{pH}$-value of 7.5, compared with samples prepared at $\mathrm{pH} 8.5$.

\subsection{Synthesis of single components}

Single components were prepared according to modified literature methods using non-enriched starting materials only. Thin film chromatography was used to determine reaction progress during synthesis and to facilitate product purification. As none of the analytes shows absorption in the UV-VIS region staining was required. The method described by Ludlam ${ }^{50,91}$ gave very useful results (cf. Supplementary Material). Table 1 lists the components which were synthesized and characterized. Details on synthesis and characterization are given in the Appendix.

\subsection{Quantitative evaluation of the ${ }^{15}$ N NMR spectra}

All spectra were processed in the same way, with identical phase and base line correction parameters. Based on the peak assignment described in Sections 4.1, 4.3, 4.4 and 4.5, the spectra were integrated with standard integration routines provided by Varian's VNMR 6.1C spectrometer software, resulting in signal areas $A_{i j}$ of the component $i$ and its individual signals $j$. These signal areas can be directly used to calculate molar amounts due to the presence of the Virtual Reference signal, which was referenced to a standard solution and represents a known molar amount of urea (see Section 3.3). The individual areas $A_{i j}$ of signal $j$ and component $i$ are divided by the stoichiometric correction factor $z_{i}$ to yield molar amounts $n_{i}$ :

$$
n_{i}=\frac{A_{i j}}{z_{i}}
$$

Here the factor $z_{i}$ is equal to the number of nitrogen centers in component $i$. The values for $z_{i}$ are listed in Table 3. To describe the distribution of individual urea units $\mathrm{NC}(=\mathrm{O}) \mathrm{N}$ over the ureaformaldehyde intermediates in the reaction mixture pseudo mole fractions $\hat{x}_{i, \mathrm{UF}}$ are introduced. From the available data these are much easier to access than actual mole fractions $x_{i}$ while being 
almost as useful to characterize the composition of the sample. The pseudo mole fractions $\hat{x}_{i, \mathrm{UF}}$ are calculated as follows:

$$
\hat{x}_{i, \mathrm{UF}}=\frac{n_{i}}{\sum_{i} n_{i, \mathrm{UF}} \cdot g_{i}}
$$

It is assumed that $\sum_{i} n_{i, \mathrm{UF}} \cdot g_{i}$ is equivalent to the initial amout of urea $n_{0, \mathrm{U}}$. This assumption is valid if all UF intermediates are correctly identified and quantified. The factor $g_{i}$ is the number of urea units $\mathrm{NC}(=\mathrm{O}) \mathrm{N}$ in component $i$ and corrects for condensation products incorporating more than one urea unit. In this way the distribution of the total inital amount of urea $n_{0, \mathrm{U}}$ among the reaction intermediates can be described. The values for $g_{i}$ are listed in Table 3 . The quantitative accuracy of these results is estimated to be $20 \%$ or better (relative deviation). The actual recovery rate (cf. Supplementary Material) of urea was compared with the expected rate by using the Virtual Reference signal. Smaller signals show a larger error and are easily overestimated due to integration errors correlated to low signal to noise ratio.

\subsection{Quantitative evaluation of the ${ }^{13} \mathrm{C}$ NMR spectra}

${ }^{15} \mathrm{~N}$ NMR spectroscopy was combined with ${ }^{13} \mathrm{C}$ NMR spectroscopy to quantify nitrogen free components. The target was to complete the samples' characterization by describing their composition in actual mole fractions $x_{i}$. A correlation was established between the ${ }^{15} \mathrm{~N}$ and ${ }^{13} \mathrm{C}$ domains by means of signals of components occurring in both domains.

$$
n_{i, \mathrm{FA}}=\frac{A_{i j}}{z_{i}} \cdot \frac{n_{M M U}+n_{D M U}}{A_{M M U}+A_{D M U}}
$$

The factor $z_{i}$ describes here the number of equivalent carbon centers giving rise to the signal $A_{i j}$ (see Table 3). These reference components were monomethylol urea and 1,3-bishydroxymethyl urea, which are both present in all samples in sufficiently large concentrations to enable reliable quantification. No Virtual Reference signal was applied to the ${ }^{13} \mathrm{C}$ domain. The amounts of methylene glycols $\mathrm{MG}_{1}$ to $\mathrm{MG}_{3}$ were quantified in samples 1 to 7 (see Table 2). After converting the 
resulting peak areas $A_{i j}$ to molar amounts (cf. Eq. (1)), the pseudo mole fractions $\hat{x}_{i, \mathrm{FA}}$ were calculated to describe the distribution of the initial amount of formaldehyde units $\mathrm{CH}_{2} \mathrm{O}$ over the components in the reaction mixture in a similar way as it was done for urea (cf. Eq. (2)). As the inital FA/U-ratio of the reaction mixture and the total amount of urea components in the mixture is known, the pseudo mole fractions $\hat{x}_{i, \mathrm{FA}}$ is calculated based on the initial amount of formaldehyde in a similar manner as $\hat{x}_{i, \mathrm{UF}}$ (cf. 3.6):

$$
\hat{x}_{i, \mathrm{FA}}=\frac{n_{i, \mathrm{FA}}}{n_{0, \mathrm{FA}}}
$$

The initial amount of formaldehyde $n_{0, \mathrm{FA}}$ is here calculated with Eq. 5, provided all UF intermediates are correctly identified and quantified:

$$
n_{0, \mathrm{FA}}=\frac{x_{0, \mathrm{FA}}}{x_{0, \mathrm{U}}} \cdot \sum_{i} n_{i, \mathrm{UF}} \cdot g_{i}
$$

The pseudo-mole fractions of water present in the reaction mixture were calculated from Eqs. (6)-9:

$$
\begin{gathered}
\hat{x}_{i, \mathrm{~W}}=\frac{n_{i, \mathrm{~W}}}{n_{0, \mathrm{~W}}+n_{\mathrm{W}, \mathrm{cond} .}-n_{\mathrm{W}, \mathrm{MGn}}} \\
n_{0, \mathrm{~W}}=n_{0, \mathrm{U}} \cdot \frac{x_{0, \mathrm{~W}}}{x_{0, \mathrm{U}}} \\
n_{\mathrm{W}, \mathrm{cond} .}=\hat{x}_{\mathrm{MDUs}} \cdot n_{0, \mathrm{U}} \\
n_{\mathrm{W}, \mathrm{MGn}}=\sum_{i} n_{i, \mathrm{MGn}}
\end{gathered}
$$

The initial amount of water $n_{0, \mathrm{~W}}$ originates from both the aqueous formaldehyde solution as well as from the water content of the buffer solution. During the reaction additional water $n_{\mathrm{W}, \text { cond. }}$ 
is formed via condensation of methylol components and urea to methylene diureas (MDUs, cf. Eq. 8). One molecule mole of water is required to form one molecule of methylene glycole. Hence this amount of water has to be removed from the water balance (cf. Eq. 9). Table 2 lists the values for $x_{0, \mathrm{U}}, x_{0, \mathrm{FA}}$ and $x_{0, \mathrm{~W}}$ for Samples 1 to 7 .

The actual mole fractions $x_{i}$ were calculated as follows:

$$
x_{i}=\frac{\hat{x}_{i,(\mathrm{UF}, \mathrm{FA}, \mathrm{W})}}{\sum_{i} \hat{x}_{i, \mathrm{UF}}+\sum_{i} \hat{x}_{i, \mathrm{FA}}+\frac{x_{0, \mathrm{~W}}}{x_{0, \mathrm{U}}} \cdot \sum_{i} \hat{x}_{i, \mathrm{~W}}}
$$

The results are discussed in Sections 4.7 and 4.8. The values $x_{0, \mathrm{U}}, x_{0, \mathrm{FA}}$ and $x_{0, \mathrm{~W}}$ describe the overall fractions for urea, formaldehyde and water. These are calculated from Eqs. (11)-(13):

$$
\begin{gathered}
x_{0, \mathrm{U}}=\frac{n_{0, \mathrm{U}}}{n_{0, \mathrm{U}}+n_{0, \mathrm{FA}}+n_{0, \mathrm{~W}}} \\
x_{0, \mathrm{FA}}=\frac{n_{0, \mathrm{FA}}}{n_{0, \mathrm{U}}+n_{0, \mathrm{FA}}+n_{0, \mathrm{~W}}} \\
x_{0, \mathrm{~W}}=1-x_{0, \mathrm{U}}-x_{0, \mathrm{FA}}
\end{gathered}
$$

\section{Results and discussion}

\subsection{Peak assignment}

First, the available single components (see Table 1) were characterized by ${ }^{1} \mathrm{H},{ }^{15} \mathrm{~N}$ and ${ }^{13} \mathrm{C}$ NMR spectroscopy. With this information, the major peaks in the spectra of the reaction mixtures could be assigned (see Table 2). Subsequently, the spectra for the samples with the three FA/U-ratios analyzed here were compared at $\mathrm{pH}$-value 8.5. Sample 4, having the lowest formaldehyde content, contains the smallest number and the least complex of the urea-formaldehyde intermediates. Here, complexity refers to the degree of substitution on urea and to the degree of addition 
of formaldehyde units to the hydroxymethyl substituents forming hemiformals. With increasing formaldehyde concentration the number of different intermediates and their complexity increases. With this knowledge and with information on the ${ }^{2} J_{\mathrm{N}, \mathrm{N}}$ coupling constant and its dependency on the chemical environment, most of the peaks in the ${ }^{15} \mathrm{~N},{ }^{13} \mathrm{C}$ and ${ }^{1} \mathrm{H}$ spectra could be assigned. Comparing the spectra of mixtures of different $\mathrm{pH}$-values facilitated assignment of condensation

products. $2 \mathrm{D}-{ }^{15} \mathrm{~N}-{ }^{15} \mathrm{~N}$ and $2 \mathrm{D}-{ }^{13} \mathrm{C}-\left\{{ }^{15} \mathrm{~N}\right\}$ NMR spectroscopy were used to confirm the identity of peaks. Tables 4 to 9 provide a list of all identified components, together with their corresponding chemical shifts for all three studied nuclei as far as applicable and available.

\subsection{Spin systems in urea-formaldehyde intermediates}

Figure 7 gives an overview on the two most relevant spin systems encountered in the reaction system. As the coupling constants are characteristic for the individual substitution patterns, their analysis proved to be valuable for peak assignment. It allows reliable assignment of signals of similar chemical shifts based on their spin environment. The first order coupling constant ${ }^{1} J_{\mathrm{H}, \mathrm{N}}$ was measured to be $\sim 90 \mathrm{~Hz} .{ }^{1} J_{\mathrm{C}, \mathrm{N}}$ is $\sim 21 \mathrm{~Hz}$ when a non-substituted proton is present at nitrogen. It is $\sim 11 \mathrm{~Hz}$ if this is not the case. The second order coupling constant ${ }^{2} J_{\mathrm{N}, \mathrm{N}}$ between the two nitrogen centers of the urea molecule was measured to be $\sim 4.5 \mathrm{~Hz}$ if one or more non substituted protons are present at each of the nitrogen centers. It is $\sim 3.5 \mathrm{~Hz}$ if one or both nitrogen centers are fully substituted.

\section{3 ${ }^{1}$ H NMR spectra}

Figure 8 shows the ${ }^{1} \mathrm{H}$ NMR spectrum of Sample 2 (see Table 2). The signals of the $\mathrm{CH}_{2}$-groups originating from methylene glycols and urea-bound hydroxymethylene groups overlap strongly with each other and also with the broad water signal. The nitrogen bound proton signals provide a much easier access to the mixture's composition, so only these were used for analysis. These signals exhibit much larger shifts with changes in their chemical environment when compared to the methylene protons. The observed signals of nitrogen bound protons can be segregated into 
two groups, depending on the degree of substitution of the amide group. As urea has two amide groups, asymmetric intermediates exhibit a minimum of two resonances from nitrogen bound protons. Single resonances originate from symmetric components or from derivatives with one fully substituted amino group. Condensates consisting of more than one urea unit can give rise to more than two signals, depending on their structure. As mentioned above, the first group of signals stems from unsubstituted amide groups and appears between 5.7 to $6.5 \mathrm{ppm}$. The signal of unsubstituted urea is found at $5.7 \mathrm{ppm}$. Substitution of one amide group of the urea molecule leads to a shift of the remaining unsubsituted group to the higher frequency. Hence the signals of the unsubstituted amide groups of all derivatives will be shifted to a higher frequency compared to the urea signal. The second group of signals consists of the resonances originating from the partly substituted amide groups. These signals appear between 6.6 and $7.5 \mathrm{ppm}$.

\section{4 ${ }^{13}$ C NMR spectra}

Figure 9 shows the ${ }^{13} \mathrm{C}$ NMR spectrum of Sample 2. The signals form two major groups. The first group represents the carbonyl signals appearing between 158 and $163 \mathrm{ppm}$. The other represents the methylene groups and exhibits a rather wide range of shifts between 45 and 95 ppm, which is subdivided into three parts, each described in detail below. In the carbonyl signal group, the resonance of urea is found at the highest frequency at $162.5 \mathrm{ppm}$. Substitution of one proton on one amide group leads to a shift of $1.5 \mathrm{ppm}$ towards higher frequencies. Each additional substitution causes a shift of $0.5 \mathrm{ppm}$ towards higher frequencies, ultimately resulting in a resonance at 158.8 ppm for trihydroxymethyl urea. As the depicted spectrum was acquired from a sample containing ${ }^{15} \mathrm{~N}$-labeled urea, a first order coupling between ${ }^{13} \mathrm{C}$ and ${ }^{15} \mathrm{~N}$ is present. Hence all carbonyl signals appear as triplets with a coupling constant ${ }^{1} J_{\mathrm{C}, \mathrm{N}}$ of $21 \mathrm{~Hz}$ (see Figure 7). The methylene range can be subdivided in three parts. From 45 to $60 \mathrm{ppm}$, the carbon centers of methylene bridges of the type $\mathrm{N}-\mathrm{CH}_{2}-\mathrm{N}$ appear. In the range of 64 to $76 \mathrm{ppm}$, resonances of hydroxymethyl groups of the types $\mathrm{N}-\mathrm{CH}_{2}-\mathrm{OH}$ and $\mathrm{N}-\mathrm{CH}_{2}-\mathrm{O}-\mathrm{R}$ are found. Hydroxymethyl groups bound to a monosubstituted amide group appear between 64.3 and $64.6 \mathrm{ppm}$, the substitution pattern of the other amide group 
leading to minor shifts here. Formation of a hemiformal by addition of formaldehyde to a hydroxymethyl group causes a shift to the higher frequency by 4 ppm, resulting in a signal group showing a resonance at ca. $69 \mathrm{ppm}$. Substitution of both protons of an $\mathrm{NH}_{2}$ group with hydroxymethyl groups leads to a shift to the higher frequency of ca. $7 \mathrm{ppm}$ over the monosubstituted amide, so the signals of the corresponding methylene groups appear between 71 and $72 \mathrm{ppm}$. In coherence with the previous finding, the resonance of the corresponding hemiformals is shifted by 4 ppm to the higher frequency to $75 \mathrm{ppm}$. Here, all methylene groups appear as doublets with a coupling constant of ${ }^{1} J_{\mathrm{C}, \mathrm{N}}=11 \mathrm{~Hz}$.

\section{5 $\quad{ }^{15} \mathrm{~N}$ NMR spectra}

The ${ }^{15} \mathrm{~N}$ NMR spectrum of Sample 3 is illustrated in Figure 10. In contrast to the previously described spectra, a sample with a high FA/U-ratio was selected here to demonstrate the presence of a large number of signals originating largely from numerous hemiformals of hydroxymethyl intermediates. The observed resonances can be divided into three groups, each representing a specific degree of substitution. These groups are spaced at intervals of $24 \mathrm{ppm}$. They can be further divided into subgroups, corresponding to the nature of the substituent on the amide group. The signals of unsubstituted amide groups are found between -304 and $-300 \mathrm{ppm}$ (relative to $\mathrm{CH}_{3} \mathrm{NO}_{2}$ ), with unsubstituted urea resonating at the lowest frequency. Substitution on the other amide group of the molecule leads to shifts to the higher frequency of $0.4 \mathrm{ppm}$ per additional hydroxymethyl group. Amide groups carrying a single hydroxymethyl group appear between -286 to -278 ppm in two subgroups: The signals of amide groups with hydroxymethyl substituents can be found between -280 and -278 ppm, while their corresponding hemiformals appear 6 ppm farther to the lower frequency. Fully substituted amide groups appear between -270 and -257 ppm in three subgroups spaced at $6 \mathrm{ppm}$. The amide groups bearing two hydroxymethyl groups contribute to the subgroup at the highest frequency at around $-258 \mathrm{ppm}$. Amide groups with one hydroxymethyl group and one hemiformal form the subgroup at ca. $-264 \mathrm{ppm}$, while the subgroup around -270 stems from amide groups with two hemiformal substituents. It should be noted that all resonances 
in spectra taken from experiments employing ${ }^{15} \mathrm{~N}$-labeled urea are doublets with a coupling constant of either 3.5 or $4.5 \mathrm{~Hz}$ (symmetric components being the only exception). As described in Section 4.2, this is due to the ${ }^{2} J_{\mathrm{N}, \mathrm{N}}$-coupling between the two ${ }^{15} \mathrm{~N}$-centers. These couplings can be used to differentiate tertiary from secondary nitrogen centers. (In case a tertiary center is present, the coupling constant is $3.5 \mathrm{~Hz}$. In all other cases it is $4.5 \mathrm{~Hz}$.) This additional information proved to be very useful assigning the $1 \mathrm{D}$ spectra and makes $2 \mathrm{D}$ NMR spectroscopy in the ${ }^{15} \mathrm{~N}$ domain possible. Four examples of ${ }^{15} \mathrm{~N}-{ }^{15} \mathrm{~N}$ and ${ }^{13} \mathrm{C}-{ }^{15} \mathrm{~N}$ correlation NMR spectroscopy are discussed here. Figure 11 shows a ${ }^{15} \mathrm{~N}$-TOCSY spectrum of Sample 3. This spectrum confirms the peak assignment based on analysis of the coupling constants. Due to the FA/U-ratio of 4, all methylol ureas, the hemiformals HF1 and HF2 and some MDUs can be identified. Figure 12 shows a ${ }^{15} \mathrm{~N}$-INADEQUATE NMR spectrum ${ }^{92}$ of the same sample. The same components as in the ${ }^{15} \mathrm{~N}$ TOCSY NMR spectrum can be assigned. In both cases no proton decoupling was used, as the patterns of the coupled signals facilitate peak assignment. Also the ${ }^{1} J_{\mathrm{C}, \mathrm{N}}$ and the ${ }^{1} J_{\mathrm{H}, \mathrm{N}}$ couplings can be utilized for correlation NMR spectroscopy. A ${ }^{13} \mathrm{C}-\left\{{ }^{15} \mathrm{~N}\right\}-$ gHMBC NMR spectrum ${ }^{93}$ of Sample 3 is depicted in Figure 13, linking the peak assignment between the ${ }^{13} \mathrm{C}$ and ${ }^{15} \mathrm{~N}$ domains. Figure 14 depicts four ${ }^{1} \mathrm{H}-\left\{{ }^{15} \mathrm{~N}\right\}$-gHSQC NMR spectra of four reaction mixtures prepared from non-enriched urea at slightly different $\mathrm{pH}$-values than the samples listed in Table 2 . Due to the indirect detection method and the high analyte concentrations, these spectra were acquired within 10-20 min. The difference between spectrum A and B illustrates the influence of the $\mathrm{pH}$-value on the amount of methylene diureas. The spectra $\mathrm{C}$ and $\mathrm{D}$ demonstrate the influence of the FA/Uratio. In $\mathrm{C}$ at $\mathrm{FA} / \mathrm{U}$-ration 4 only methylol ureas and their hemiformals are present, there is no unreacted urea. The spectrum of sample D in contrast contains significant amounts of unreacted urea and methylol ureas of low substitution degree. Also present are methylene diureas and small amounts of hemiformals. However, the main value of these ${ }^{1} \mathrm{H}_{-}{ }^{15} \mathrm{~N}$ correlations is the deconvolution of peaks in the ${ }^{1} \mathrm{H}$ domain with regard to individual components, as the degree of overlap is significant. 


\subsection{Changes in chemical shift upon addition of formaldehyde}

Figure 15 illustrates the systematic changes in chemical shift in the ${ }^{15} \mathrm{~N}$ NMR spectrum of functional groups of methylol ureas containing $\mathrm{NH}_{2}$ - and NHR-groups upon addition of formaldehyde. Substitution of a proton on these functional groups with a hydroxymethyl group leads to a shift to the higher frequency of the directly affected nitrogen center of $24 \mathrm{ppm}$. The other (non-affected) nitrogen center is shifted to lower frequencies by $0.4-0.6 \mathrm{ppm}$, if it is not fully substituted itself. If it is a fully substituted tertiary nitrogen center ( $\mathrm{NR}_{2}$-group), it shifts $0.4 \mathrm{ppm}$ to higher frequencies. Addition of formaldehyde to hydroxymethyl groups leads to the corresponding hemiformals. This results in a shift to higher frequencies of $6 \mathrm{ppm}$ compared to the directly affected nitrogen centers. The signals of the other, non-affected nitrogen centers shift 0.4 to $0.6 \mathrm{ppm}$ to lower frequencies if they are not fully substituted and $0.4 \mathrm{ppm}$ to higher frequencies if they are fully substituted. The observed shifts in the ${ }^{1} \mathrm{H}$ - and ${ }^{13} \mathrm{C}$-spectrum are summarized in Table 10.

\subsection{Quantitative analysis of $1 \mathrm{D}-{ }^{15} \mathrm{~N}$ NMR spectra}

Following the method described in Section 3.6, pseudo mole fractions $\hat{x}_{i, \mathrm{UF}}$ were derived from the $1 \mathrm{D}-{ }^{15} \mathrm{~N}$ NMR spectra. They represent the distribution of urea over the individual intermediates in the samples with regard to the initial amount of urea $n_{0, \mathrm{U}}$ at the start of the reaction. Table 11 lists the numerical results. Figure 16 shows the ${ }^{15} \mathrm{~N}$ NMR spectra of Samples $1-3$. Figure 17 depicts a graphical representation of the results for the distribution of urea in the samples. Figure 18 shows the corresponding ${ }^{1} \mathrm{H}$ NMR spectra.

- At FA/U-ratio 1 and pH 7.5 (Sample 1), $42 \%$ of the urea is present as monomethylol urea (MMU) and 3.5\% as its hemiformal (HF1-n). 15\% exists as symmetric dimethylol urea (DMU) and 5.5\% as its hemiformal (HF2- $0 n$ ). The asymmetric 1,1-dimethylol urea ( $a$ DMU) contributes $1.5 \%$ to the total. About $3.6 \%$ is converted to methylene diurea (MDU). However, $25 \%$ of the urea (U) is still present in its unreacted form in the mixture.

- At FA/U-ratio 1 and pH 8.5 (Sample 4), about $45 \%$ of the urea is converted to monomethylol 
urea (MMU) and 2.2\% to its hemiformal (HF1-n). 18\% is present as symmetric dimethylol urea (DMU), 4.4\% as its hemiformal (HF2-0n). Asymmetric 1,1-dimethylol urea ( $a$-DMU) contributes at $1.4 \%$. Only $1.3 \%$ is present as methylene diurea (MDU).

- At FA/U-ratio 2 and pH 7.5 (Sample 2), the ratio between monosubstituted monomethylol urea and 1,3-dimethylol urea shifts in favor of the latter. Monomethylol urea (MMU) represents 22\%, 1,3-dimethylol urea (DMU) 34.4\%, asymmetric 1,1-dimethylol urea ( $a$-DMU) $3.4 \%$ and trimethylol urea (TMU) about $9 \%$ of the total, which amounts to about $70 \%$ of urea in the mixture. The hemiformal of monomethylol urea (HF1-n) represents 5.9\%. The hemiformals of DMU, contributing 13.2\% together, can be subdivided into HF2-0n, which carries one oligomeric hydroxymethyl group and HF2-mn carrying two of these groups. These hemiformals contribute $11.4 \%$ and $1.8 \%$. The hemiformals of trimethylol urea (TMU) represent $3.7 \%$ of the total, consisting of $1.8 \%$ HF $4-m n 0$ and $1.9 \%$ HF4-0np. Altogether, the hemiformals amount to $22.8 \%$ of the reaction mixture. $2.6 \%$ of total urea is present as methylene diurea (MDU). Only $2.7 \%$ of urea (U) remains unreacted.

- At FA/U-ratio 2 and pH 8.5 (Sample 6), monomethylol urea (MMU) represents 27.5\%, 1,3dimethylol urea (DMU) 43\%, asymmetric 1,1-dimethylol urea ( $a$-DMU) $4.1 \%$ and trimethylol urea (TMU) about $8.5 \%$ of the total, which amounts to about $83.3 \%$ of urea in the mixture. The hemiformals here make up $12.8 \%$ of the total. The hemiformal of monomethylol urea (HF1-n) contributes 4.4\%, the hemiformals of DMU contribute 6.2\% (HF2-0n) and 2.2\% (HF2-mn). No HF4 was determined. Only $0.3 \%$ of urea is present as MDU, while $3.5 \%$ is present as unreacted urea $(\mathrm{U})$.

- At FA/U-ratio 4 and pH 7.5 (Sample 3), no unreacted urea (U) was detected. 5\% of total urea is present as monomethylol urea (MMU). The largest fraction exists as 1,3-di- and trimethylol urea (DMU, TMU), contributing $30 \%$ and $23.6 \%$ to the total. Asymmetric 1,1dimethylol urea ( $a$-DMU) represents $2.6 \%$. The hemiformals of DMU amount to $15.4 \%$ as HF2-0n and 9.1\% as HF2-mn, while those of TMU contribute $8.7 \%$ as HF4- $m n 0$ and 
5.7\% as HF4-0np. Together, the hemiformals amount to almost 38.9\%. No hemiformal of monomethylol urea (HF1- $n$ ) and no methylene diureas (MDUs) were detected.

- At FA/U-ratio 4 and pH 8.5 (sample 7), no unreacted urea (U) was detected. $5.7 \%$ of total urea is present as monomethylol urea (MMU). 1,3-dimethylol urea (DMU) represents $28.3 \%$, asymmetric 1,1-dimethylol urea ( $a$-DMU) $2.6 \%$ and trimethylol urea $22.1 \%$ of total urea. The hemiformals of DMU contribute $17.9 \%$ as HF2-0n and $8.6 \%$ as HF2-mn to the total, while those of TMU exist to $9.8 \%$ as HF4-mn0 and to $4.4 \%$ as HF4-0np. Together, the hemiformals amount to almost $41.3 \%$. Only $0.3 \%$ hemiformal of monomethylol urea (HF1$n$ ) and no methylene diurea (MDU) were detected. When comparing the composition of the samples taken at $\mathrm{pH}$-value 7.5 and 8.5 , there is consistently more methylene diurea (MDU) present in the samples with $\mathrm{pH} 7.5$, for a given FA/U-ratio (see Section 4.8 and Table 12). This indicates a higher condensation rate at the lower $\mathrm{pH}$-value. Consequently, at this $\mathrm{pH}-$ value the fractions of monomethylol urea intermediates are decreasing while the fractions of the corresponding hemiformals are increasing. The formation of one intermediate of the methylene diurea type requires two urea units and one formaldehyde unit, which leads to the observed shift in composition. An increase in the FA/U-ratio from 1 to 2 leads to a decrease in the fraction of unreacted urea $(\mathrm{U})$ by one order of magnitude. The fraction of monomethylol urea (MMU) also decreases by about 50\%, while the fraction of dimethylol urea (DMU) significantly increases. Also, the fractions of all hemiformals (HF) increase. Trimethylol urea (TMU) is detectable at a FA/U-ratio of 2, while it is not present at a FA/U-ratio of 1. There are differences in sample composition between $\mathrm{pH} 7.5$ and 8.5, but comparing the different FA/U-ratios at constant $\mathrm{pH}$-value reveals the same tendencies for both $\mathrm{pH}$-values.

At FA/U-ratio 2 there is less methylene diurea (MDU) present. Despite an increase in formaldehyde content, the condensation rate is lower. Increasing the FA/U-ratio from 2 to 4 leads to a concentration of urea $(\mathrm{U})$ which is below the detection limit. Consequently the fraction of hydroxymethyleneurea (MMU) is also further reduced. The fraction of dimethylol urea (DMU) decreased while the fraction of trimethylol urea (TMU) increases significantly. The fractions of all hemifor- 
mals except HF1- $n$ also increase. These observations are very similar for $\mathrm{pH}$-values 7.5 and 8.5. In both cases, no methylene diurea (MDU) is detected. The observed coexistence of dimethylol urea (DMU), hemiformals (HF) and urea (U) is remarkable. The hydroxymethyl group shows a higher affinity towards formaldehyde than the amide group of unreacted urea. From the fact that a decrease in the fraction of unsubstituted $\mathrm{NH}_{2}$-groups leads to a decrease in the fraction of condensation products, it may be concluded that the availability of both unsubstituted $\mathrm{NH}_{2}$-groups and hydroxymethyl groups determines the rate of the condensation reaction.

\subsection{Quantitative analysis of $1 \mathrm{D}-{ }^{13} \mathrm{C}$ NMR spectra}

The $1 \mathrm{D}-{ }^{13} \mathrm{C}$ NMR spectra were analyzed in order to gain access to the concentration of unreacted formaldehyde in the samples, which is present in the form of methylene glycols (see Figure 19). Furthermore, with this information the mole fractions $x_{i}$ became accessible, which enable complete description of the sample's composition (see Section 3.7). The results are given in Table 12. The signals of the methylene glycols $\mathrm{MG}_{1}, \mathrm{MG}_{2}$ and $\mathrm{MG}_{3}$ were evaluated, with $\mathrm{MG}_{2}, \mathrm{MG}_{3}$ and higher methylene glycols not being present at low FA/U-ratios. This finding is in fair agreement with the

results of Hahnenstein et. al. ${ }^{33}$. The primary parameter influencing the methylene glycol content of the mixtures is the FA/U-ratio. At a FA/U-ratio of 1 and 2, only $2-3 \%$ and $4-5 \%$ of the initial amount of formaldehyde does not react with urea. At a FA/U-ratio of 4, this fraction increases to about $6-7 \%$. It is remarkable that the ratio between formaldehyde bound in hemiformals of methylol ureas and formaldehyde bound in methylene glycols is rather high and varies between 3.9 and 13.7. Hence the reaction of formaldehyde with hydroxymethyl groups is more favorable than the competing reaction with water, although the latter is present at a large molar excess over methylol ureas.

\subsection{Uron-type structures}

Some authors postulate the formation of 1,3,5-oxadiazinane-4-on (uron) and its corresponding hydroxymethyl derivatives during various steps of the manufacturing process of urea-formaldehyde 
resins $39,75,78,94$. Figure 20 shows the formation pathways of the three simplest examples of these intermediates. Formation of these components during the hydroxymethylation stage of the production process under the conditions described in Section 3.4 could not be confirmed. However, it was possible to synthesize these structures via alternative methods and characterize them by NMR spectroscopy in the ${ }^{1} \mathrm{H},{ }^{13} \mathrm{C}$ and ${ }^{15} \mathrm{~N}$ domain. In the ${ }^{13} \mathrm{C}$ NMR spectrum, the resonances of these components are characteristic and straightforward to identify. Here, the carbonyl resonances are shifted towards higher frequencies when comparing to non-cyclic intermediates and appear between 154.8 and 156.5 ppm. None of the reaction mixtures prepared in this study exhibited detectable levels of these components. Direct synthesis of dimethoxymethylene uron via intramolecular condensation of methylol ureas and subsequent removal of the methoxy hydroxymethyl succeeded (see Section 3.5 and Appendix). However, considering the reaction conditions it seems possible that these ring structures form during manufacture of fiber boards.

\section{Conclusion}

The hydroxymethylation stage of the synthesis of urea-formaldehyde resins was studied by ${ }^{1} \mathrm{H}$, ${ }^{13} \mathrm{C}$ and ${ }^{15} \mathrm{~N}$ NMR spectroscopy with regard to the distribution of intermediates and their identity. Several intermediates were identified for the first time by using $1 \mathrm{D}-{ }^{15} \mathrm{~N}$ NMR spectroscopy. The results were confirmed by $2 \mathrm{D}$ NMR spectroscopy and by direct synthesis. The change in ${ }^{15} \mathrm{~N}$ chemical shift of the nitrogen centers of urea upon addition of formaldehyde was determined. The existence of hemiformals of methylol ureas was confirmed and their chemical shifts were determined. No uron-type structures were identified under the studied conditions, but these structures were prepared otherwise and characterized. It was shown that reaction mixtures as they are commonly used in the industrial production of urea-formaldehyde resins can be quantitatively analyzed by a combination of ${ }^{15} \mathrm{~N}$ and ${ }^{13} \mathrm{C}$ NMR spectroscopy, resulting in a detailed description of the mixtures' composition at different feed ratios and $\mathrm{pH}$-values. The variation in $\mathrm{pH}$-value lead to a slight change in mixture composition due to the acid-catalyzed condensation reactions, but did not mea- 
surably affect hydroxymethylation and formation of hemiformals. The results open a new route for characterizing the studied complex mixtures and ultimately for optimizing the UF resin production based on the knowledge of the true composition of the reacting mixtures. 


\section{References}

(1) Keim, W. Kunststoffe; Wiley-VCH Verlag, 2006.

(2) Tanga, X.; Bai, Y.; Duong, A.; Smith, M. T.; Li, L.; Zhang, L. Environ. Int. 2009, 35, 12101224.

(3) Dunky, M.; Niemz, P. Holzwerkstoffe und Leime; Springer-Verlag, Berlin Heidelberg, 2002.

(4) Kadowaki, H. Bull. Chem. Soc. Jpn. 1936, 11, 248-261.

(5) Smythe, L. E. Journal of Physical and Colloid Chemistry 1947, 51, 369-378.

(6) Smythe, L. E. J. Am. Chem. Soc. 1951, 73, 2735-2738.

(7) Smythe, L. E. J. Am. Chem. Soc. 1953, 75, 1508-1510.

(8) Crowe, G. A.; Lynch, C. C. J. Am. Chem. Soc. 1948, 70, 3795-3797.

(9) Crowe, G. A.; Lynch, C. C. J. Am. Chem. Soc. 1949, 71, 3731-3733.

(10) de Jong, J. Recl. Trav. Chim. Pay. B. 1950, 69, 1566.

(11) de Jong, J.; de Jonge, J. Recl. Trav. Chim. Pay. B. 1953, 72, 139-156.

(12) de Jong, J.; de Jonge, J. Recl. Trav. Chim. Pay. B. 1953, 72, 169-172.

(13) de Jong, J.; de Jonge, J. Recl. Trav. Chim. Pay. B. 1953, 72, 1027-1036.

(14) de Jong, J.; de Jonge, J. Recl. Trav. Chim. Pay. B. 1953, 72, 213-217.

(15) de Jong, J.; de Jonge, J. Recl. Trav. Chim. Pay. B. 1952, 71, 890-898.

(16) de Jong, J.; de Jonge, J. Recl. Trav. Chim. Pay. B. 1952, 71, 643-660.

(17) de Jong, J.; de Jonge, J.; Eden, H. A. K. Recl. Trav. Chim. Pay. B. 1953, 72, 88-90.

(18) de Jong, J.; de Jonge, J.; Eden, H. A. K. Recl. Trav. Chim. Pay. B. 1952, 71, 661-667. 
(19) Landqvist, N. Acta Chem. Scand. 1955, 9, 1127-1142.

(20) Landqvist, N. Acta Chem. Scand. 1955, 9, 1459-1465.

(21) Landqvist, N. Acta Chem. Scand. 1955, 9, 1466-1470.

(22) Landqvist, N. Acta Chem. Scand. 1955, 9, 1471-1476.

(23) Landqvist, N. Acta Chem. Scand. 1955, 9, 1477-1483.

(24) Landqvist, N. Acta Chem. Scand. 1956, 10, 244-248.

(25) Landqvist, N. Acta Chem. Scand. 1957, 11, 776-779.

(26) Landqvist, N. Acta Chem. Scand. 1957, 11, 792-803.

(27) Landqvist, N. Acta Chem. Scand. 1957, 11, 780-785.

(28) Landqvist, N. Acta Chem. Scand. 1957, 11, 786-791.

(29) Kveton, R. Collect. Czech. Chem. Commun. 1956, 21, 593-606.

(30) BFA, Formaldehyd - Gefährlicher als bisher angenommen? Stellungnahme vom 29. November 2004; 2004.

(31) Walker, J. F. Formaldehyde, 3rd ed.; ACS Monograph Series, 1964.

(32) Hasse, H.; Maurer, G. Ind. Eng. Chem. Res. 1991, 30, 2195-2200.

(33) Hahnenstein, I.; Albert, M.; Hasse, H.; Kreiter, C. G.; Maurer, G. Ind. Eng. Chem. Res. 1995, $34,440-450$.

(34) Kambanis, S. M.; Vasishth, R. C. J. Appl. Polym. Sci. 1971, 15, 1911-1919.

(35) Chiavarini, M.; Delfanti, N.; Bigatto, R. Angew. Makromol. Chem. 1975, 46, 151-162.

(36) Ebdon, J. R.; Heaton, P. E. Polymer 1977, 18, 971-974. 
(37) Dankelman, W.; Daemen, J. M. H.; de Breet, A. J. J.; Mulder, J. L.; Huysmans, W. G. B.; de Wit, J. Angew. Makromol. Chem. 1976, 54, 187-201.

(38) de Breet, A. J. J.; Dankelman, W.; Huysmans, W. G. B.; de Wit, J. Angew. Makromol. Chem. 1977, 62, 7-31.

(39) Tomita, B.; Hatono, S. J. Polym. Sci., Part A: Polym. Chem. 1978, 16, 2509-2525.

(40) Rammon, R.; Johns, W. E.; Magnuson, J.; Dunker, K. J. Adhesion 1986, 19, 115-135.

(41) Kim, M. G.; Amos, L. W. Chem. Ber. 1990, 29, 208-212.

(42) Christjanson, P.; Pehk, T.; Siimer, K. J. Appl. Polym. Sci. 2006, 100, 1673-1680.

(43) Siimer, K.; Christjanson, P.; Kaljuvee, T.; Pehk, T.; Lasn, I.; Saks, I. J. Therm. Anal. Calorim. 2008, 92, 19-27.

(44) Despres, A.; Pizzi, A.; Pasch, H.; Kandelbauer, A. J. Appl. Polym. Sci. 2007, 106, 1106-1128.

(45) Ebdon, J.; Heaton, P. E.; Huckerby, T. N.; O’Rourke, W. T. S.; Parkin, J. Polymer 1984, 25, 821.

(46) Ebdon, J.; Hunt, B. J.; O’Rourke, W. T. S.; Parkin, J. Brit. Polym. J. 1988, 20, 327-334.

(47) Thomson, R. A.; Manley-Harris, M.; Gill, B. D. Magn. Reson. Chem. 2003, 41, 622-625.

(48) Angelatos, A. S.; Burgar, M. I.; Dunlop, N.; Separovic, F. J. Appl. Polym. Sci. 2004, 91, 3504-3512.

(49) Philbrook, A.; Blake, C. J.; Dunlop, N.; Easton, C. J.; Keniry, M. A.; Simpson, J. S. Polymer 2005, 46, 2153-2156.

(50) Steinhof, O. NMR-spektroskopische Aufklärung des bei der Umsetzung von Harnstoff mit Formaldehyd auftretenden Reaktionsnetzwerks; PhD thesis. Cuvillier Verlag Göttingen: Universität Stuttgart, 2010. 
(51) Kibrik, E. J.; Steinhof, O.; Scherr, G.; Thiel, W. R.; Hasse, H. J. Appl. Polym. Sci. (submitted 2013),

(52) Schecker, H. G.; Jost, W. Ber. Bunsen-Ges. Phys. Chem. 1969, 73, 521.

(53) Schecker, H. G.; Schulz, G. Z. Phys. Chem. (Frankfurt, Ger.) 1969, 65, 221.

(54) Hahnenstein, I.; Hasse, H.; Kreiter, C. G.; Maurer, G. Ind. Eng. Chem. Res. 1994, 33, 10221029.

(55) Hahnenstein, I.; Hasse, H.; Liu, Y.-Q.; Maurer, G. AIChE Symp. Ser. 1994, 90, 141-157.

(56) Dahn, H.; Pechy, P. Magn. Reson. Chem. 1996, 34, 723-724.

(57) Maiwald, M.; Fischer, H. H.; Kim, Y. K.; Hasse, H. Anal. Bioanal. Chem. 2003, 375, 11111115.

(58) Maiwald, M.; Fischer, H. H.; Ott, M.; Peschla, R.; Kuhnert, C.; Kreiter, C. G.; Maurer, G.; Hasse, H. Ind. Eng. Chem. Res. 2003, 42, 259-266.

(59) Kuhnert, C.; Albert, M.; Breyer, S.; Hahnenstein, I.; Hasse, H.; Maurer, G. Ind. Eng. Chem. Res. 2006, 45, 5155-5164.

(60) Cannizzaro, S. Liebigs Ann. Chem. 1853, 88, 129-130.

(61) Luther, D.; Koch, H. Chem. Ber. 1966, 99, 2227.

(62) Ott, M.; Fischer, H. H.; Maiwald, M.; Albert, K.; Hasse, H. Chem. Eng. Process. 2005, 44, $653-660$.

(63) Glutz, B. R.; Zollinger, H. Helv. Chim. Acta 1969, 52, 1976-1984.

(64) Kibrik, E. J.; Steinhof, O.; Scherr, G.; Thiel, W. R.; Hasse, H. J. Polym. Res. 2013, 20, Article 79. 
(65) Kibrik, E. J.; Steinhof, O.; Scherr, G.; Thiel, W. R.; Hasse, H. J. Appl. Polym. Sci. 2012, 128, 3957-3963.

(66) Goldschmidt, C. J. Prakt. Chem. 1897, 46, 460.

(67) Zigeuner, G.; Fitz, H. Monatsh. Chem. 1959, 90, 211-221.

(68) Chuang, I. S.; Maciel, G. E. Macromolecules 1992, 25, 3204-3226.

(69) Siimer, K.; Pehk, T.; Christjanson, P. Macromol. Symp. 1999, 148, 149-156.

(70) Christjanson, P.; Lasn, I.; Siimer, K.; Pehk, T. Holz als Roh- und Werkstoff 2002, 60, 379384.

(71) Christjanson, P.; Pehk, T.; Siimer, K. Proc. Estonian Acad. Sci. Chem. 2006, 55, 212-225.

(72) Zigeuner, G.; Knierzinger, W.; Voglar, K.; Wiesenberger, E.; Sobotka, M. Monatsh. Chem. 1951, 82, 847-855.

(73) Kveton, R. Collect. Czech. Chem. Commun. 1959, 24, 2068.

(74) Horn, V.; Benndorf, G.; Rädler, K. P. Plaste Kautsch. 1978, 25, 570.

(75) Soulard, C.; Kamoun, C.; Pizzi, A. J. Appl. Polym. Sci. 1999, 72, 277-289.

(76) Mejdell, T.; Schjønsby, H. K. Macromol. Symp. 2004, 206, 241-254.

(77) Beachem, M. T.; Schickedanz, P. D.; Oppelt, J. C.; Maier, D. V.; Cowen, F. M. J. Org. Chem. 1963, 28, 1876.

(78) Gao, W.; Li, J. Maderas. Ciencia y tecnologia 2012, 14, 3-12.

(79) Meessen, J. H. Ullmann's Encyclopedia of Industrial Chemistry 2010,

(80) Harris, R. K.; Becker, E. D.; Menezes, S. M. C. D.; Goodfellow, R.; Granger, P. Pure Appl. Chem. 2001, 73, 1795-1818. 
(81) Claridge, T. D. High-Resolution NMR Techniques in Organic Chemistry, 1st ed.; Elsevier Ltd., Oxford, 1999.

(82) Malz, F. Quantitative NMR-Spektroskopie als Referenzverfahren in der analytischen Chemie; PhD thesis.: Humboldt-Universität zu Berlin, 2003.

(83) Malz, F.; Jancke, H. J. Pharm. Biomed. Anal. 2005, 38, 813-823.

(84) Maiwald, M.; Steinhof, O.; Hasse, H. Nachr. Chem. 2007, 55, 745-749.

(85) Maiwald, M.; Steinhof, O.; Sleigh, C.; Bernstein, M.; Hasse, H. In Quantitative HighResolution Online NMR Spectroscopy in Pharmaceutical Reaction and Process Monitoring.; Holzgrabe, U., Wawer, I., Diehl, B., Eds.; Elsevier, 2008; Vol. NMR Spectroscopy in Pharmaceutical Analysis; Chapter 8, pp 471-491.

(86) Maiwald, M. Hochauflösende Online-NMR-Spektroskopie für das Reaktions- und Prozeßmonitoring - Beispiele zur Anwendung in der Verfahrenstechnik; Habilitation. Cuvillier Verlag Göttingen: Technische Universität Kaiserslautern, 2012.

(87) Harris, R. K.; Becker, E. D.; Menezes, S. M. C. D.; Granger, P.; Hoffman, R. E.; Zilm, K. W. Pure Appl. Chem. 2008, 80, 59-84.

(88) Mahon, H. P. Rev. Sci. Instrum. 1969, 40, 1644.

(89) Akoka, S.; Barantin, L.; Trierweiler, M. Anal. Chem. 1999, 71, 2554-2557.

(90) Billault, I.; Robins, R.; Akoka, S. Anal. Chem. 2002, 74, 5902-5906.

(91) Ludlam, P. R. Analyst 1973, 98, 107-115.

(92) Buddrus, J.; Bauer, H. Angew. Chem., Int. Ed. 1987, 26, 625-642.

(93) Niemczura, W. P.; Helms, G. L.; Chesnick, A. S.; Moore, R. E.; Bornemann, V. J. Magn. Reson. 1989, 81, 635-640. 
(94) Tomita, B.; Hirose, Y. J. Polym. Sci., Part A: Polym. Chem. 1976, 14, 387-401.

(95) Murray, T. P. J. Labelled Compd. Radiopharm. 1985, 22, 1251-1259.

(96) Paquin, A. M. J. Org. Chem. 1949, 14, 189-193. 


\section{Figures}

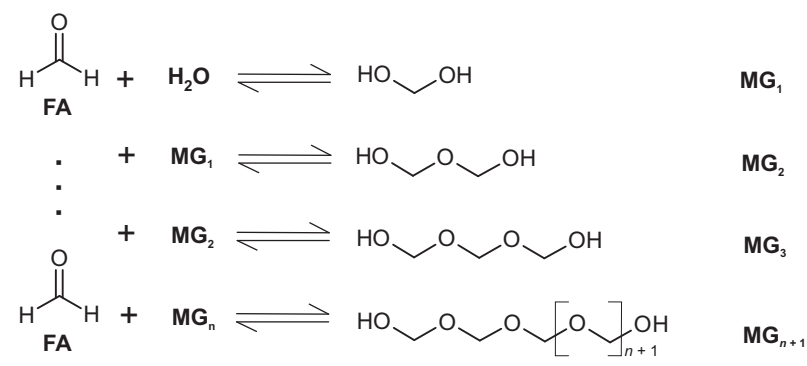

Figure 1: Chemical reactions in the formaldehyde-water system. Molecular formaldehyde $\mathrm{CH}_{2} \mathrm{O}$ reacts with water to form oligomeric methylene glycols. 


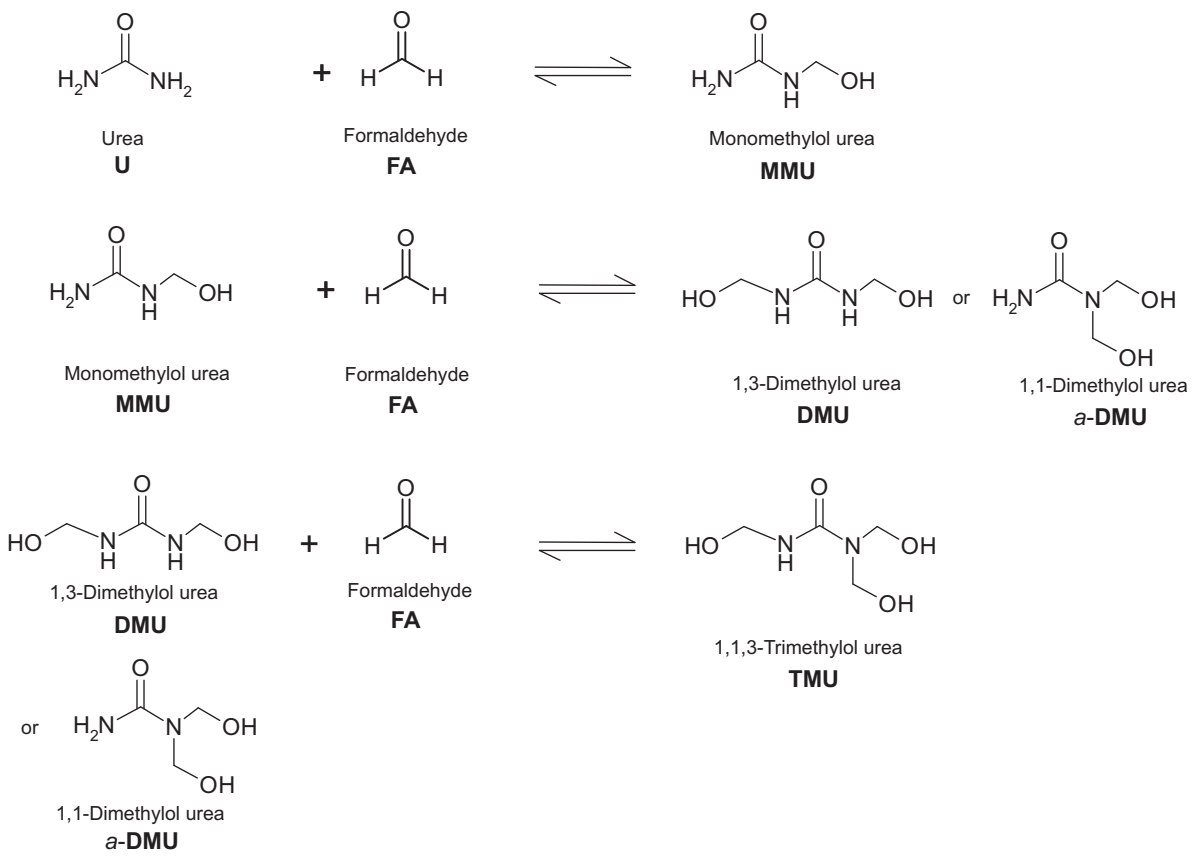

Figure 2: Hydroxymethylation of urea. Up to three molecules of formaldehyde can add to urea. 


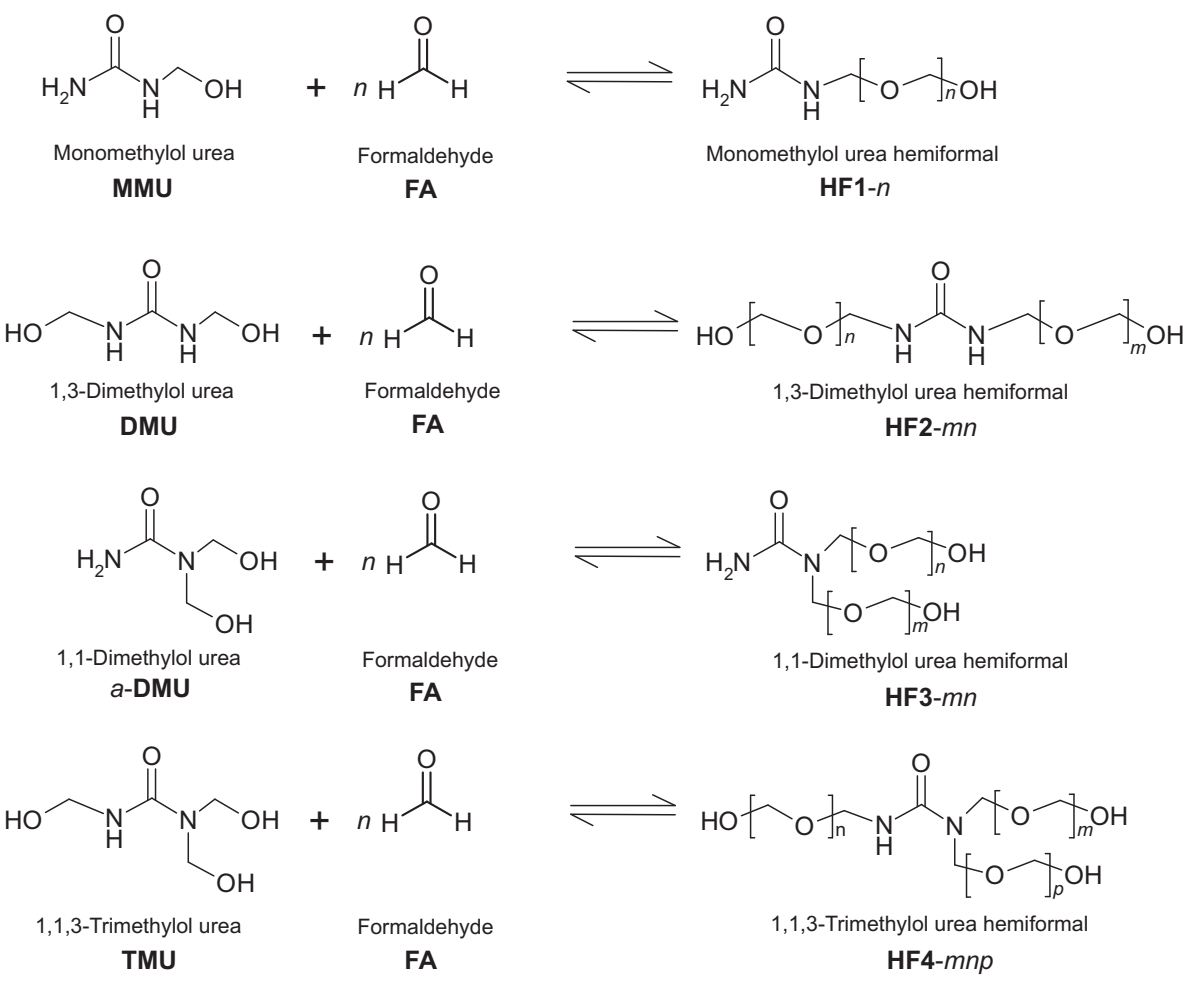

Figure 3: Overview of reactions of formaldehyde with the hydroxymethyl groups of monomethylol urea leading to different hemiformals. 
a)

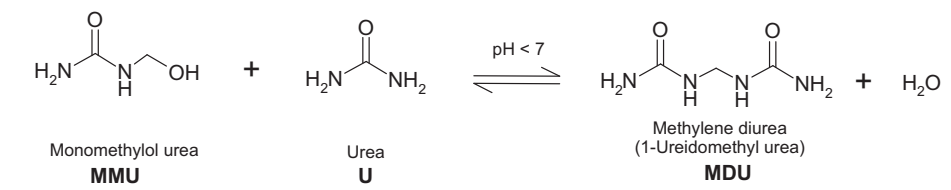

b)

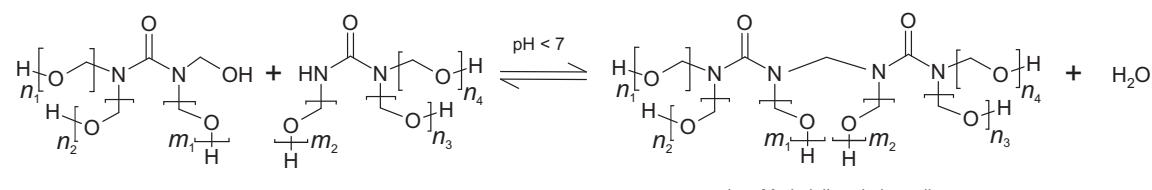

$n m$-Methylol urea $\quad n m$-Methylol urea

(nm-Methylol)methylene diurea

Figure 4: Condensation reactions in the urea-formaldehyde system, formation of methylenebridged intermediates; a) formation of methylene diurea; b) general description of the condensation to methylene diureas. 


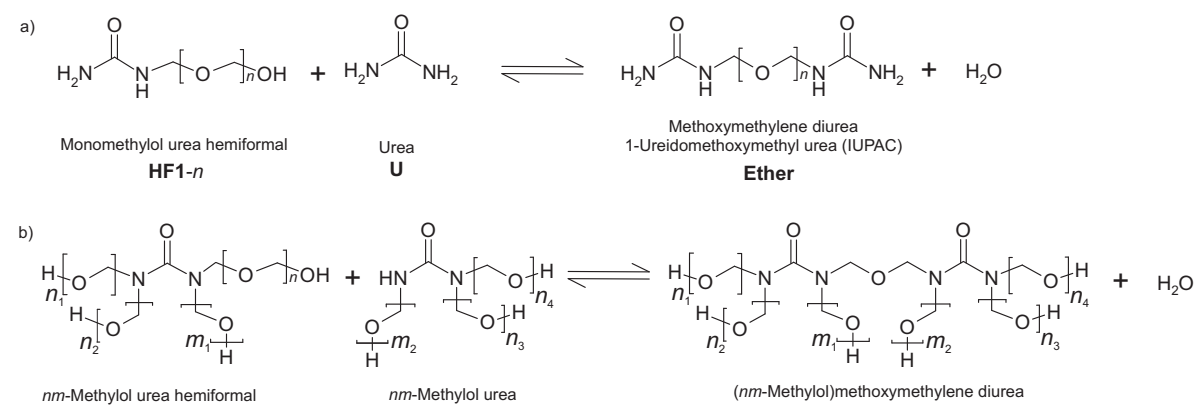

Figure 5: Condensation reactions in the urea-formaldehyde system, formation of ether-bridged intermediates; a) formation of methoxymethylene diurea from hemiformal HF1- $n$ and urea; b) general description of the condensation to methoxymethylene diurea. 


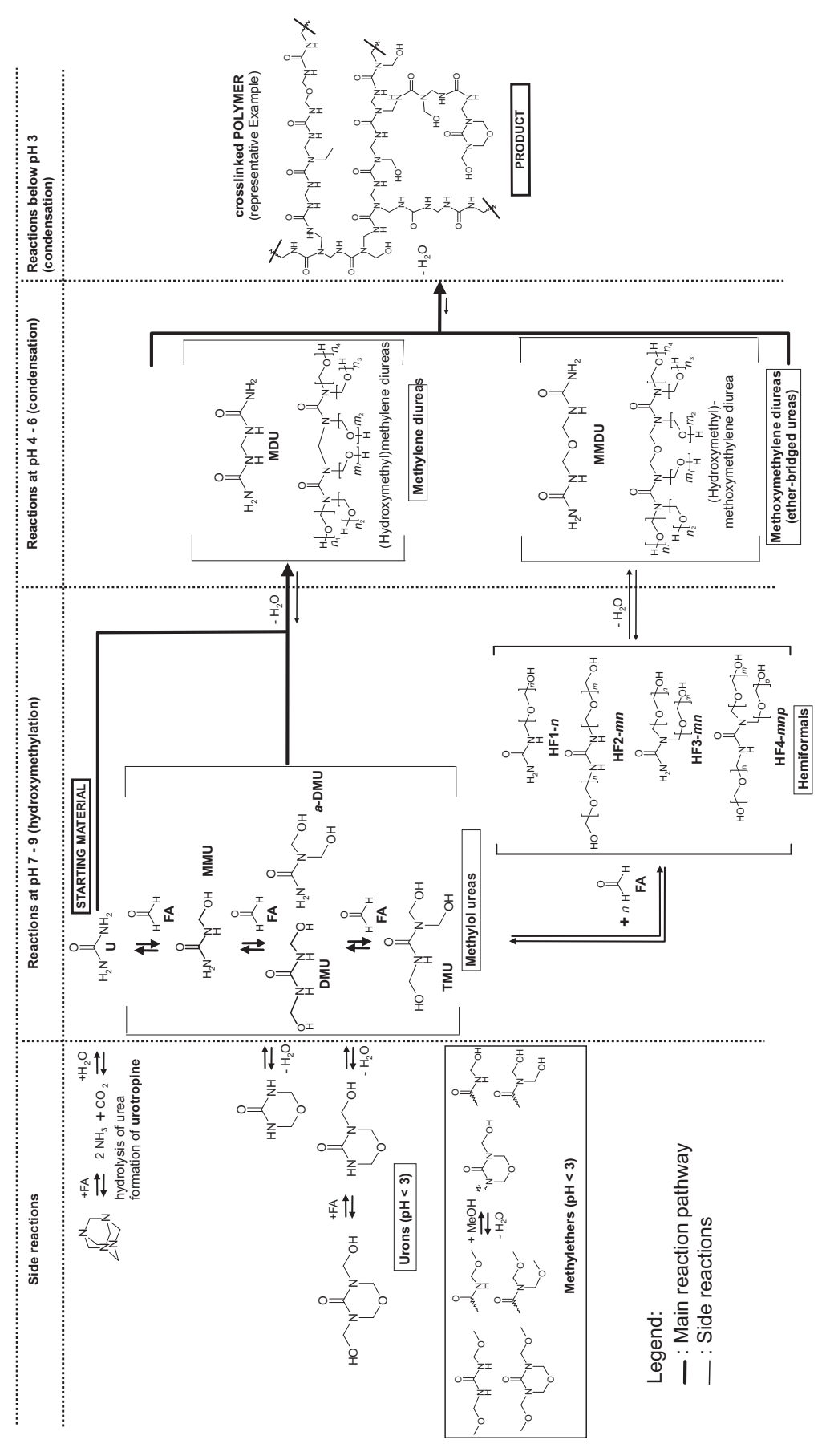

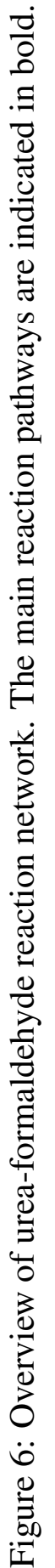




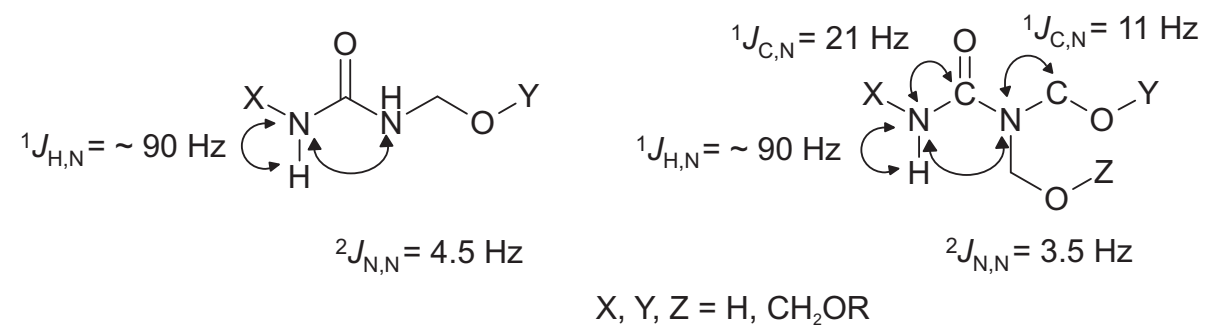

Figure 7: NMR-spectroscopic coupling constants in monomethylol urea, as observed in this work. 


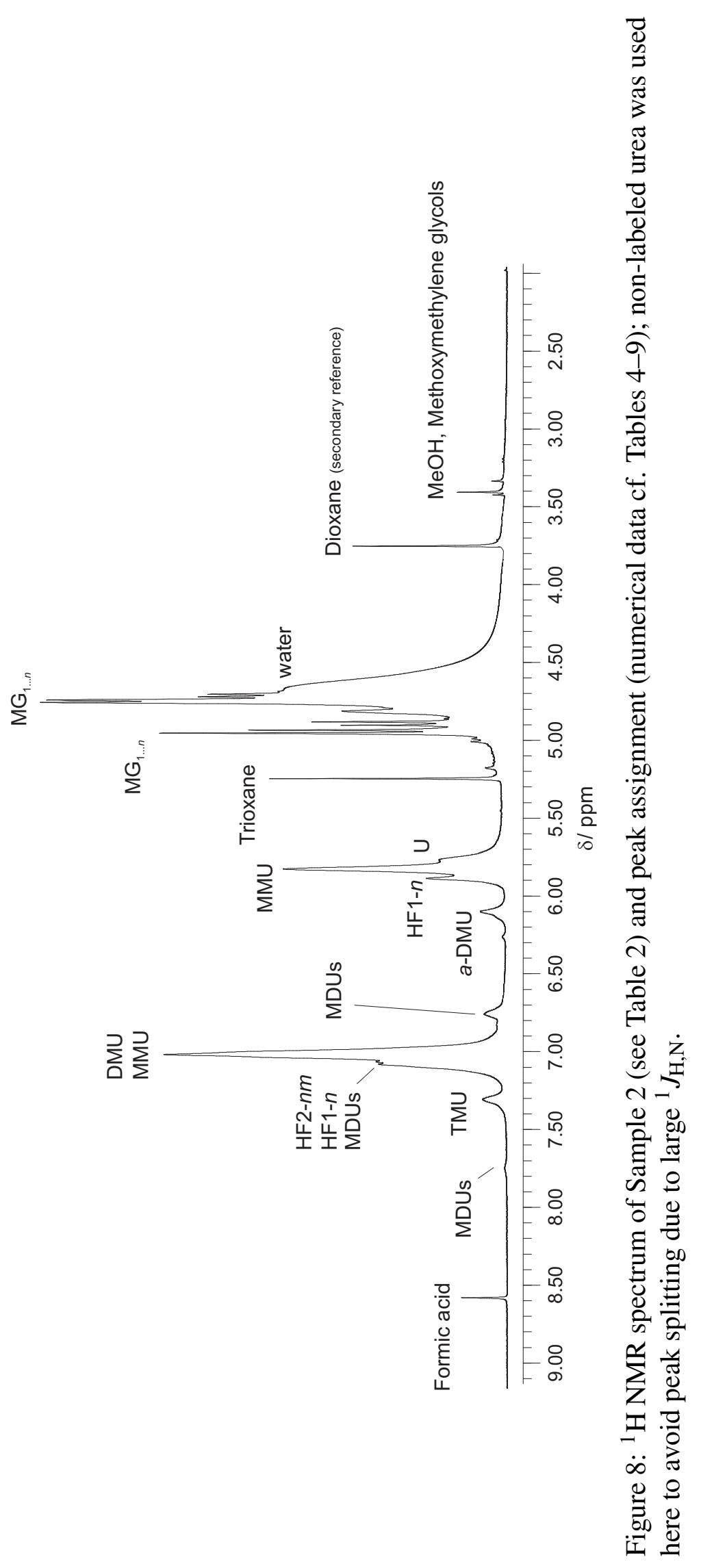




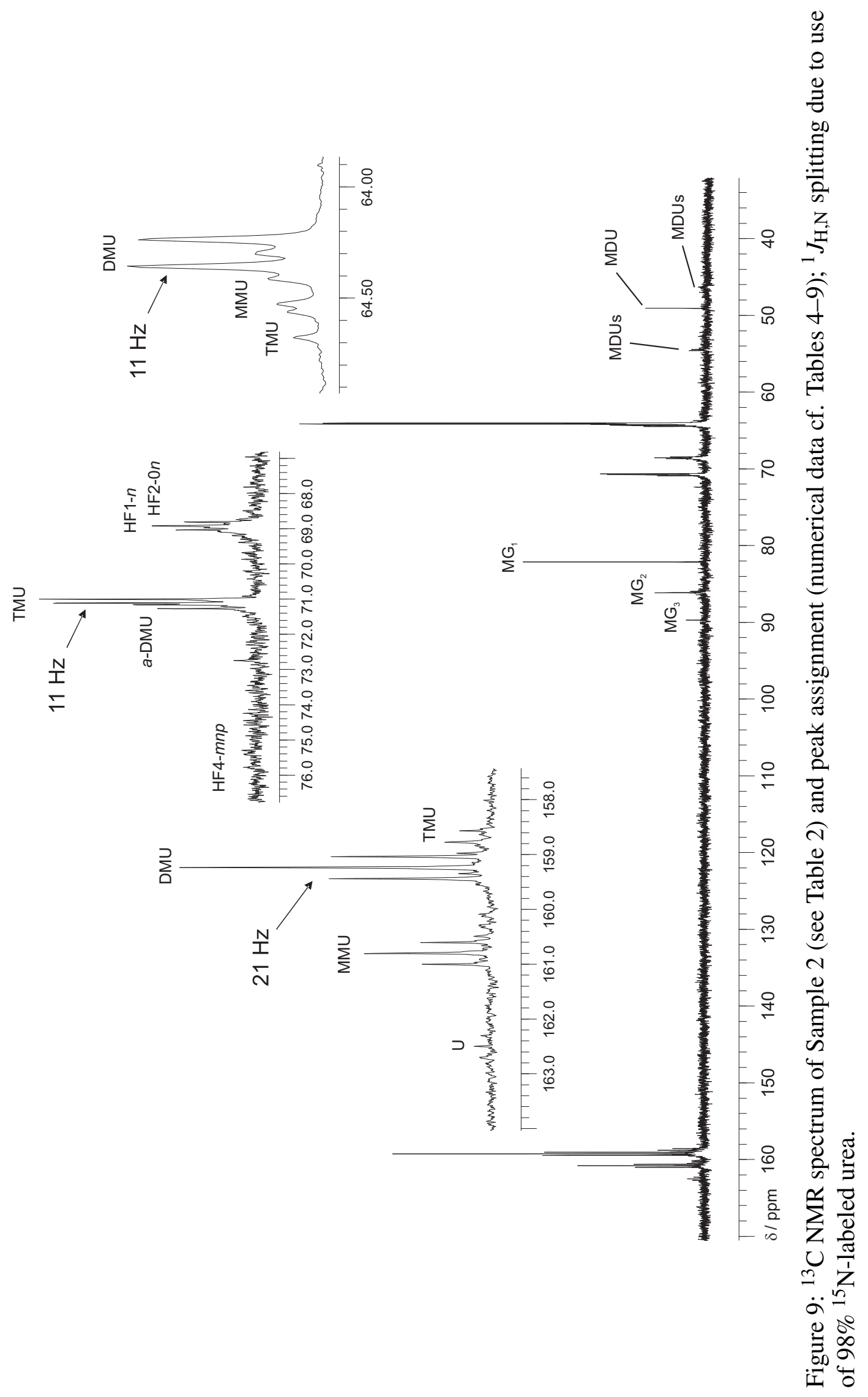




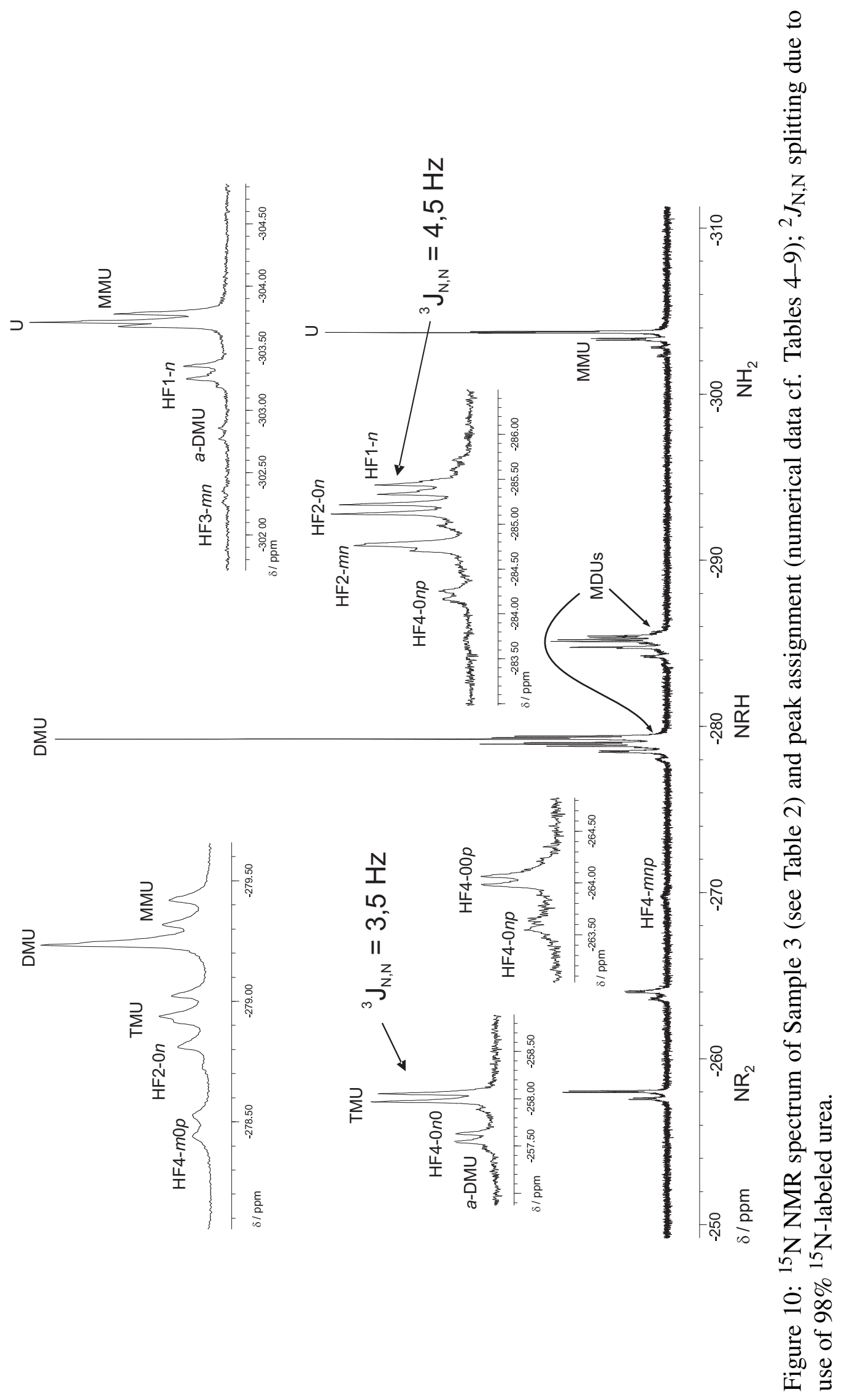




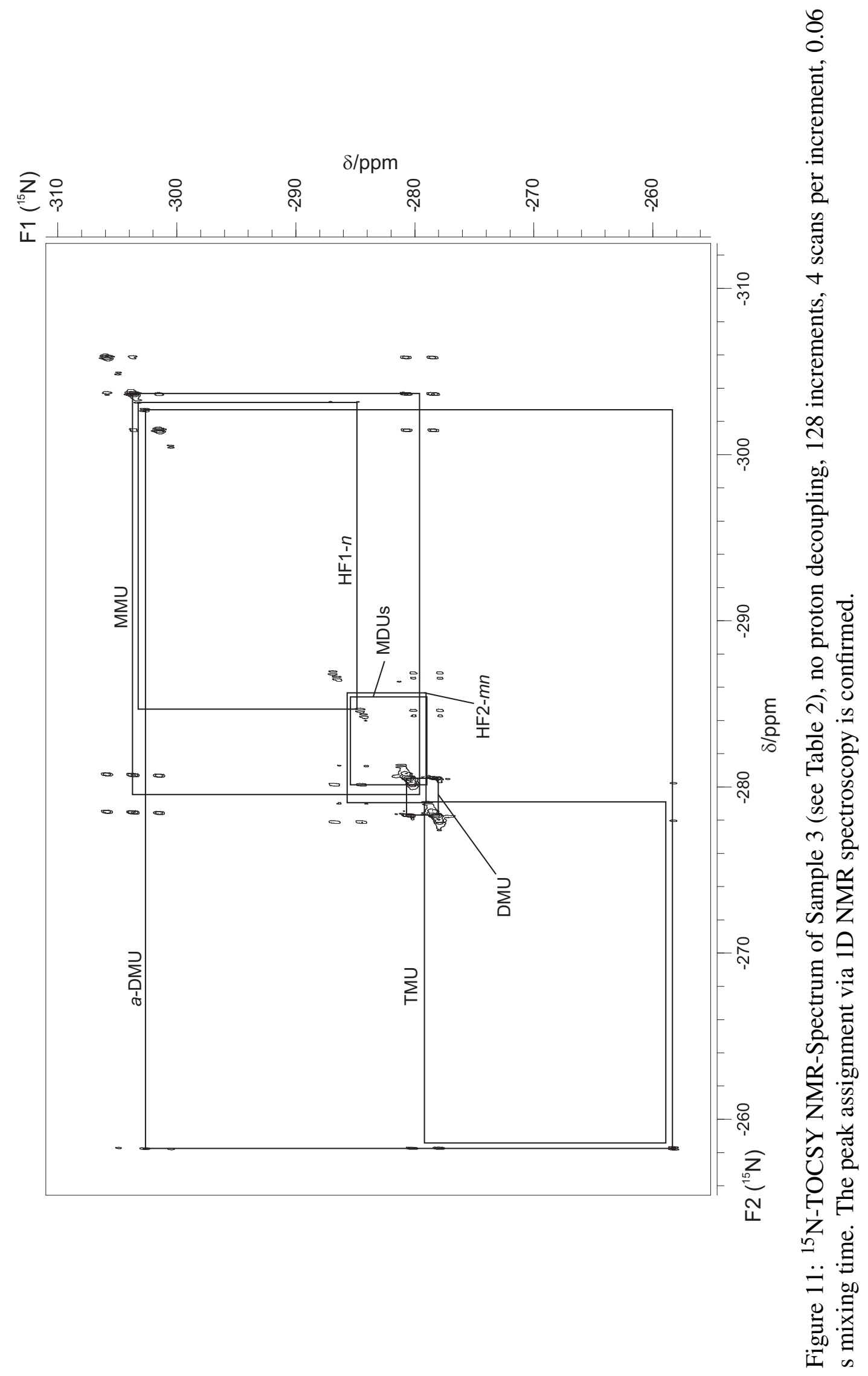




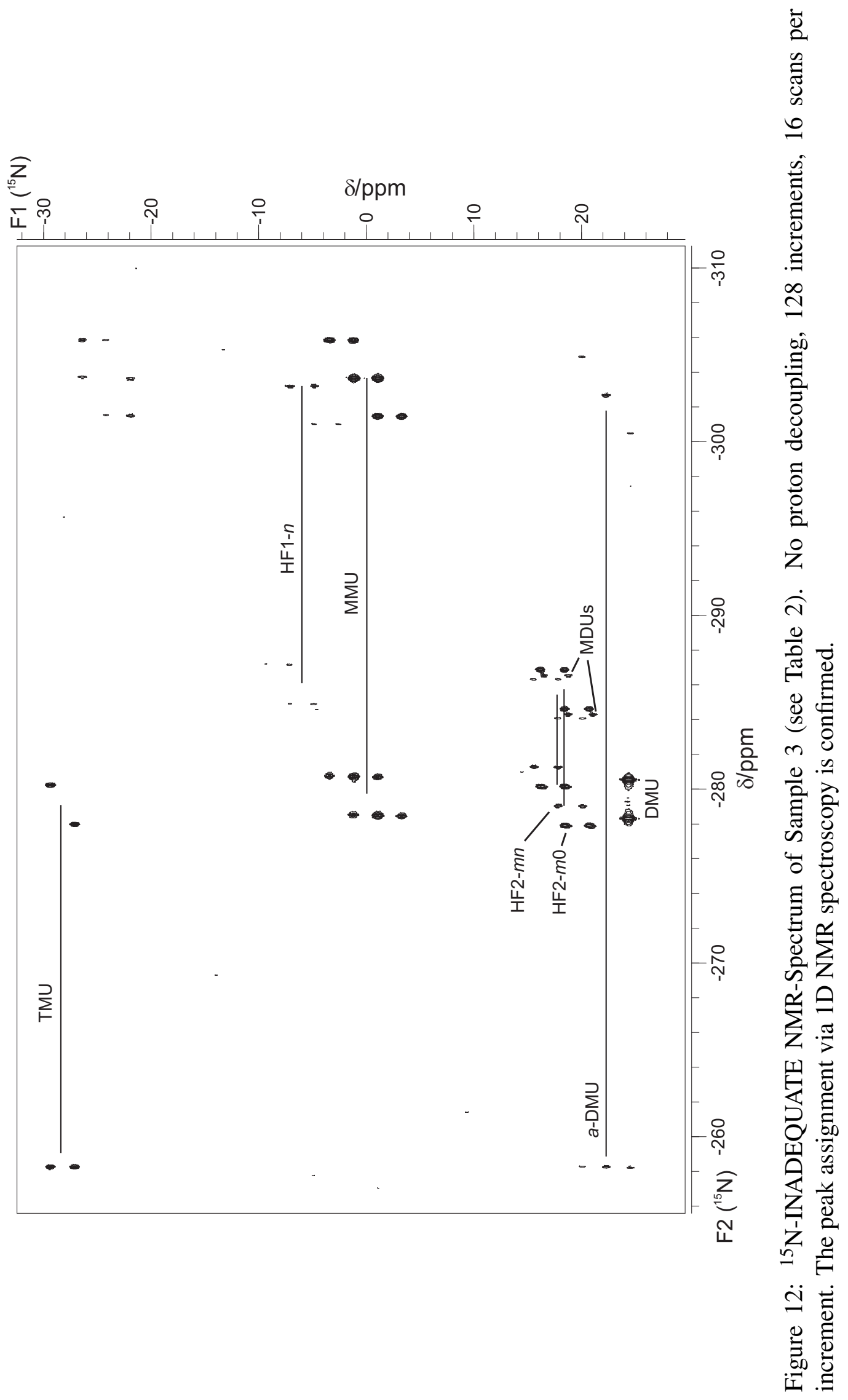




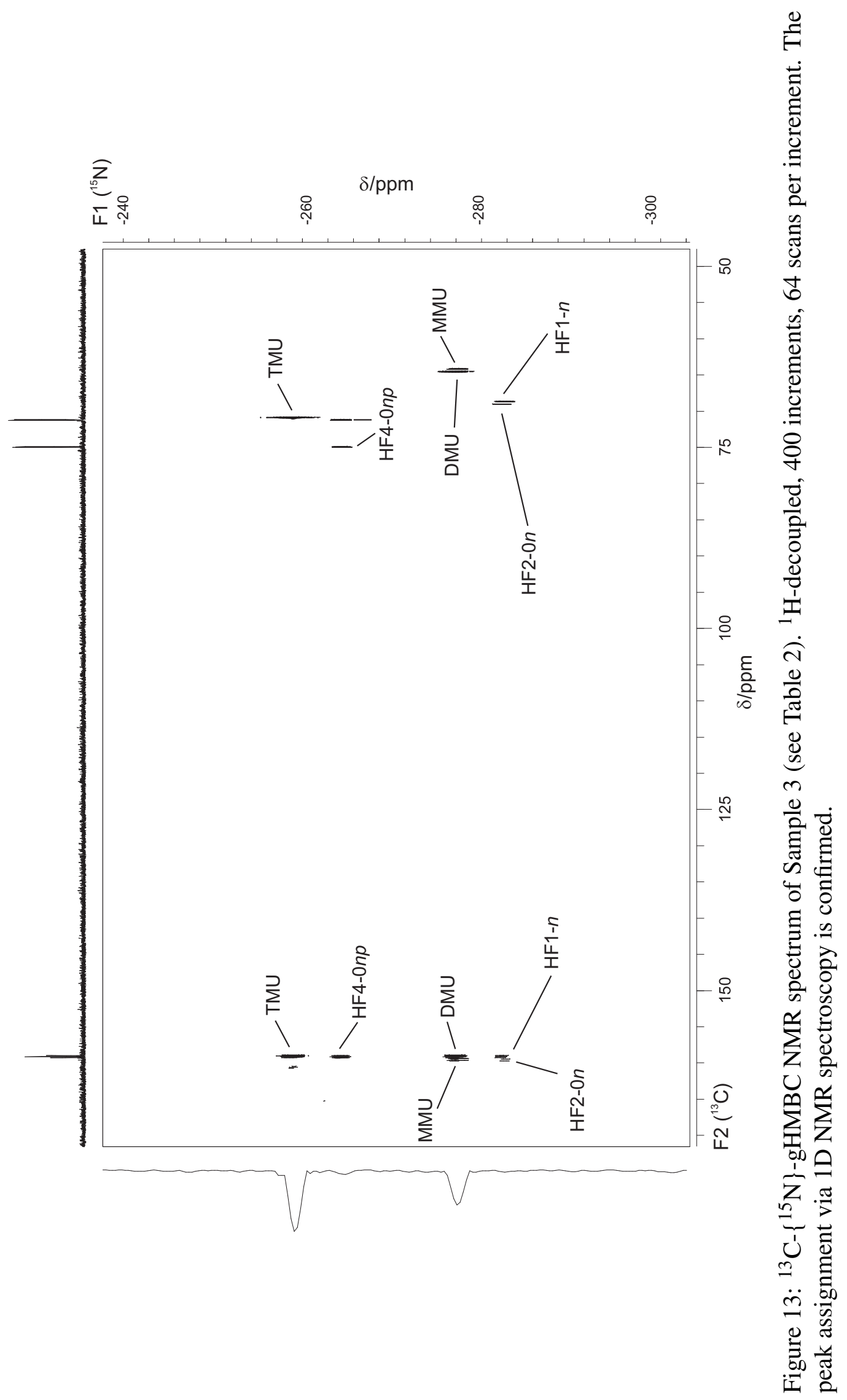




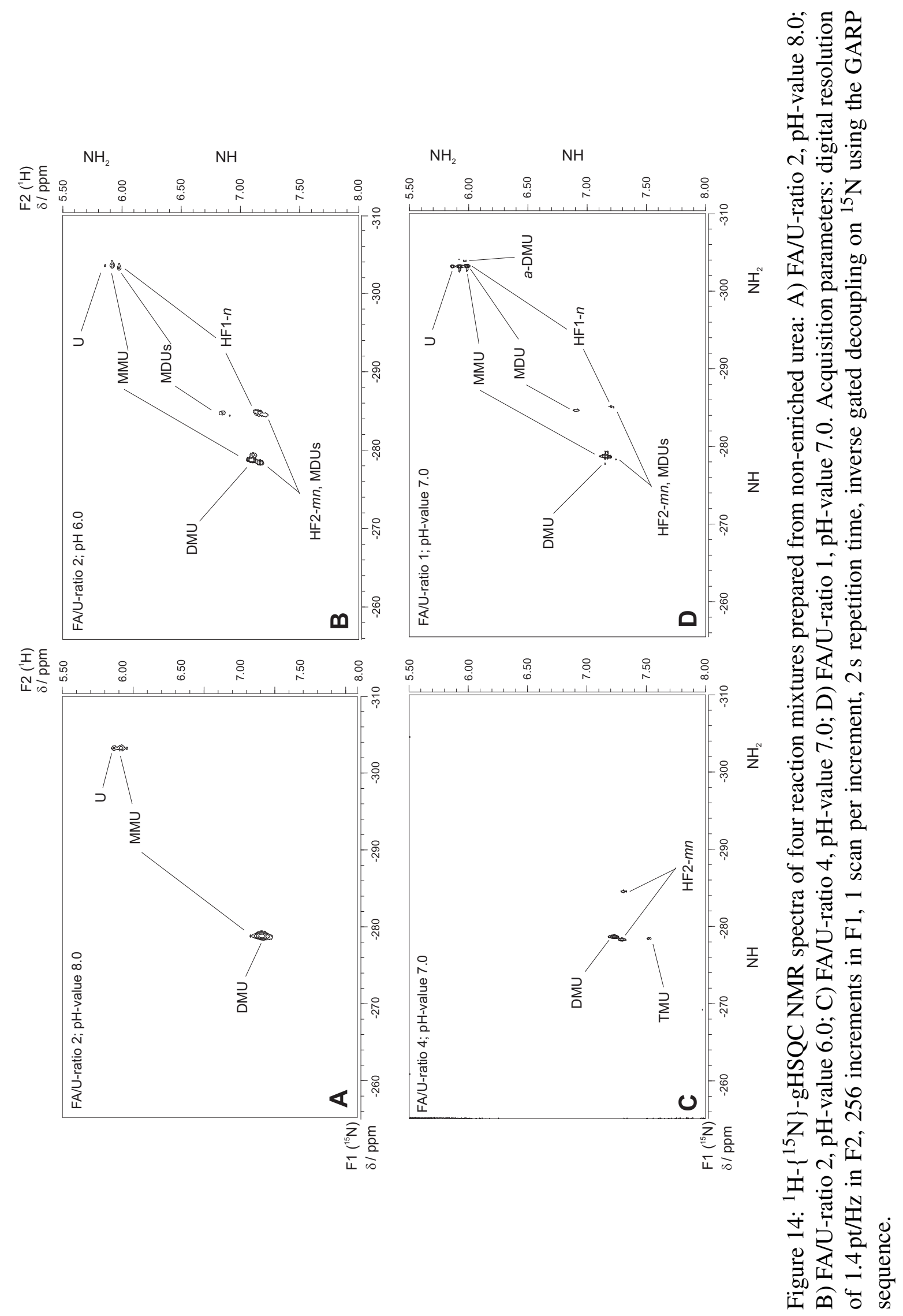



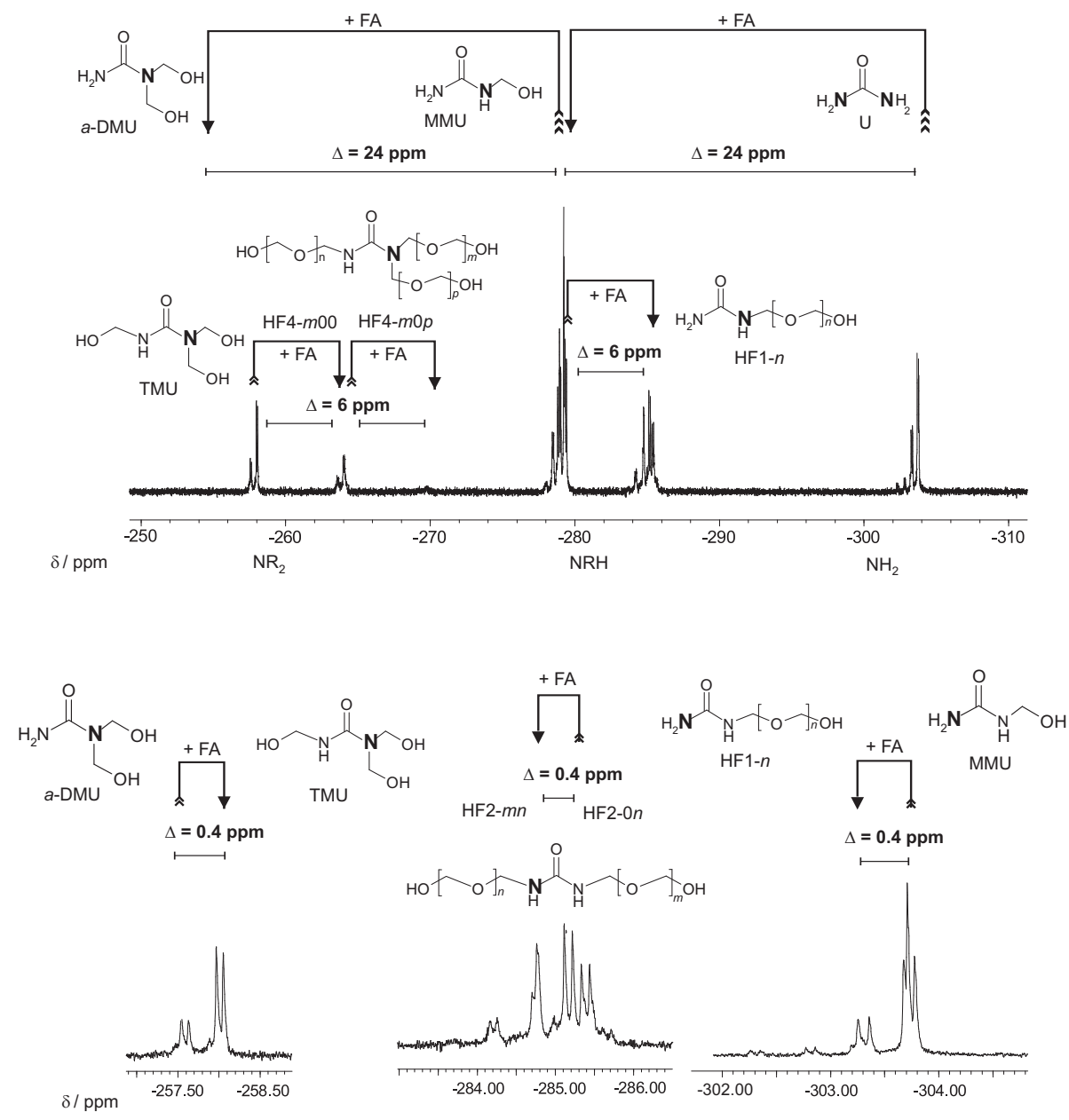

Figure 15: NMR-spectroscopic chemical shifts caused by addition of formaldehyde to urea. The directly affected nitrogen centers shift by $24 \mathrm{ppm}$ to lower frequencies, while the indirectly affected nitrogen centers shift only $0.4 \mathrm{ppm}$. There is a shift of $6 \mathrm{ppm}$ to the lower frequency upon addition of a formaldehyde unit to an existing hydroxymethyl group. (cf. Table 10 for numerical data). 

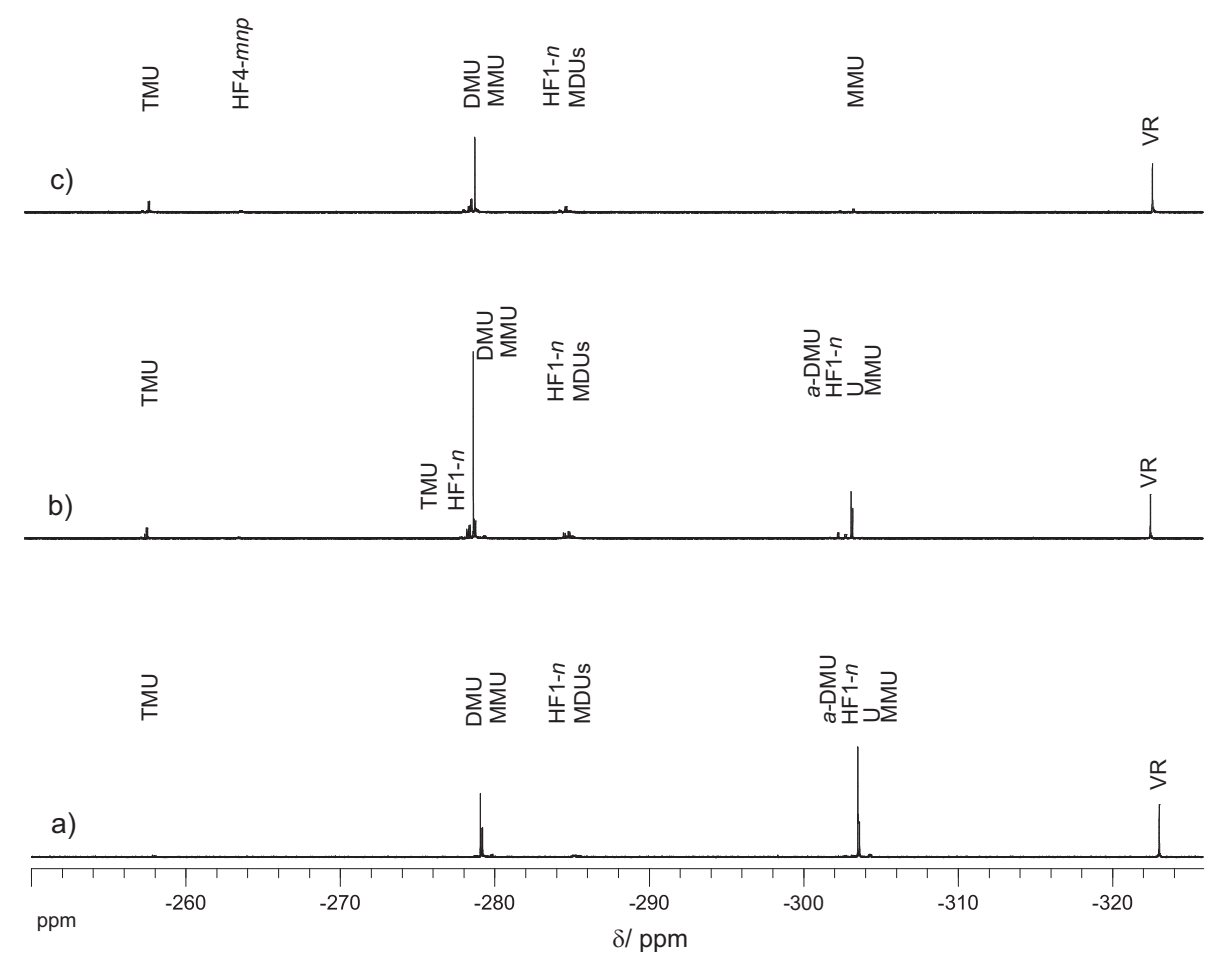

Figure 16: ${ }^{15} \mathrm{~N}$ NMR spectra of a) Sample 1, b) Sample 2 and c) Sample 3 (FA/U-ratios 1, 2 and 4, all pH 7.5, cf. Table 2). 


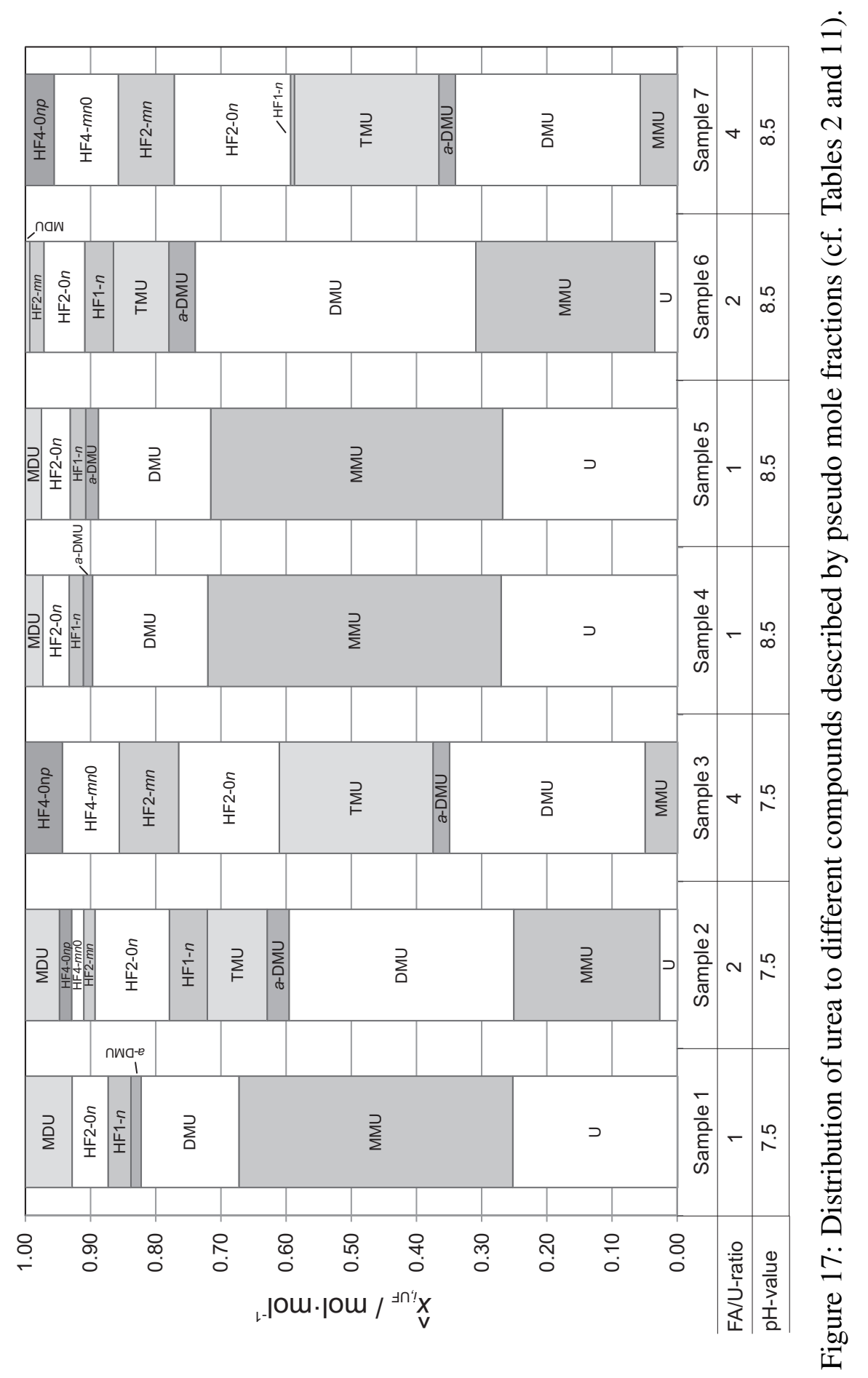




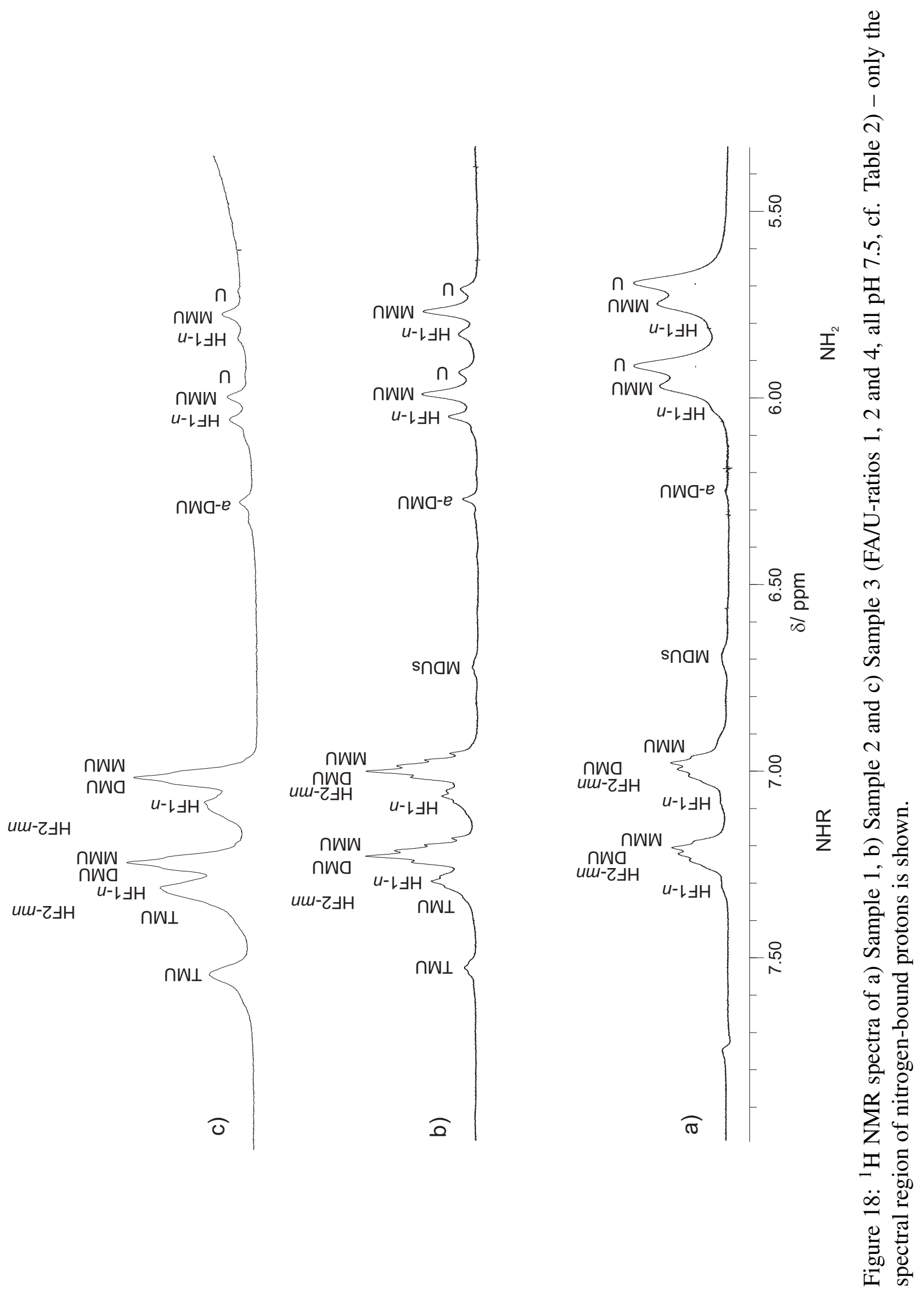




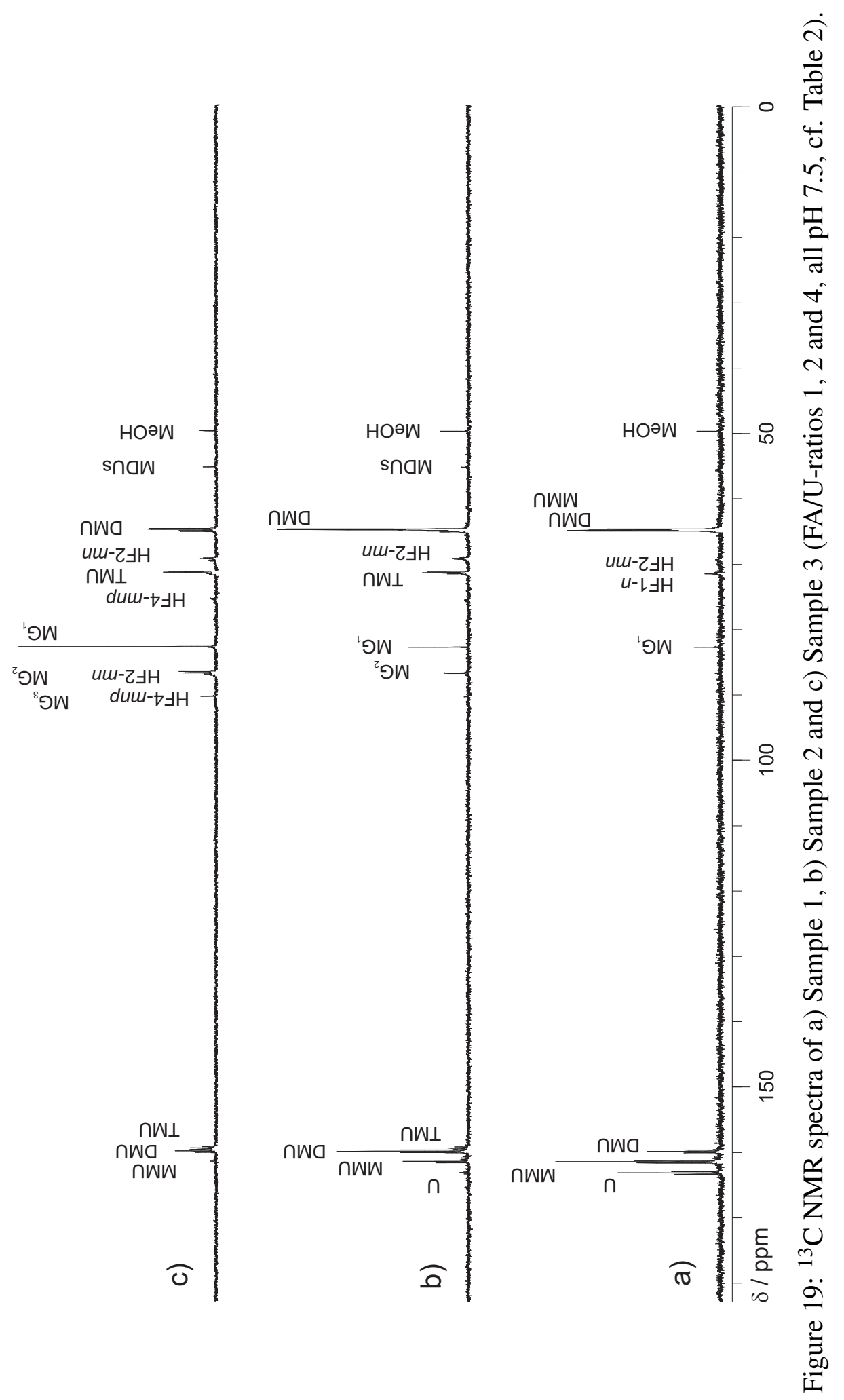




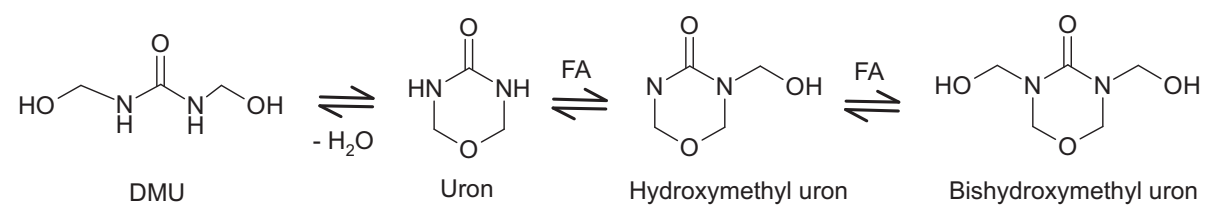

Figure 20: Formation of 1,3,5-Oxadiazinanes (Urons) and their hydroxymethyl derivatives. 


\section{Tables}

Table 1: Synthesized and characterized Urea-formaldehyde intermediates.

\begin{tabular}{|l|l|}
\hline Component & Abbreviation \\
\hline \hline Monomethylol urea & MMU \\
\hline 1,3-Dimethylol urea & DMU \\
\hline 1-Ureidomethyl urea & MDU \\
\hline 1-Hydroxymethyl-3-(3-hydroxymethylureidomethyl) urea & DM-MDU \\
\hline 1,3-Bis-methoxymethyl urea & - \\
\hline 1,3,5-Oxadiazinan-4-on & Uron \\
\hline 3-Hydroxymethyl-1,3,5-oxadiazinan-4-on & Hydroxymethyl uron \\
\hline 3,5-Bis-hydroxymethyl-1,3,5-oxadiazinan-4-on & Bishydroxymethyl uron \\
\hline
\end{tabular}


Table 2: Composition and reaction conditions of the reaction mixtures analyzed in this work.

\begin{tabular}{|c||c|c|c||c|c|c|}
\hline Sample-Nr. & FA/U-ratio & pH-value & Buffer conc. & Formaldehyde & Urea & Water \\
\hline & $\mathbf{m o l} / \mathbf{m o l}$ & & $\mathbf{m o l} / \mathbf{l}$ & \multicolumn{3}{|c|}{$x_{i}$} \\
\hline \hline 1 & 1 & 7.5 & 1.0 & 0.059 & 0.059 & 0.881 \\
\hline 2 & 2 & 7.5 & 1.0 & 0.140 & 0.070 & 0.789 \\
\hline 3 & 4 & 7.5 & 1.0 & 0.115 & 0.029 & 0.855 \\
\hline 4 & 1 & 8.5 & 1.0 & 0.059 & 0.059 & 0.881 \\
\hline 5 & 1 & 8.5 & 0.1 & 0.059 & 0.059 & 0.881 \\
\hline 6 & 2 & 8.5 & 1.0 & 0.140 & 0.070 & 0.789 \\
\hline 7 & 4 & 8.5 & 1.0 & 0.115 & 0.029 & 0.855 \\
\hline
\end{tabular}


Table 3: Formaldehyde-urea intermediates: Number of signals $j$ in the ${ }^{15} \mathrm{~N}$ NMR spectrum of component $i$ consisting of peaks $A_{i j}$ (in case of $\mathrm{MG}_{1}$ to $\mathrm{MG}_{3}$ this refers to the peaks in the ${ }^{13} \mathrm{C}$ NMR spectrum), stoichiometric factors $z_{i}$, number of urea units $g_{i}$ and number of formaldehyde units $f_{i}$ for the analyzed components.

\begin{tabular}{|l|l|c|c|c|c|}
\hline Intermediate & Abbreviation & $j$ & $z_{i}$ & $g_{i}$ & $f_{i}$ \\
\hline \hline Urea & $\mathrm{U}$ & 1 & 2 & 1 & 0 \\
\hline Monomethylol urea & $\mathrm{MMU}$ & 2 & 2 & 1 & 1 \\
\hline 1,3-Dimethylol urea & $\mathrm{DMU}$ & 1 & 2 & 1 & 2 \\
\hline 1,1-Dimethylol urea & $a$-DMU & 2 & 2 & 1 & 2 \\
\hline Trimethylol urea & $\mathrm{TMU}$ & 2 & 2 & 1 & 3 \\
\hline Monomethylol urea hemiformal & $\mathrm{HF} 1-n$ & 2 & 2 & 1 & 2 \\
\hline 1,3-Dimethylol urea hemiformals & $\mathrm{HF} 2-0 n$ & $1 . . n$ & 2 & 1 & 3 \\
\hline 1,3-Dimethylol urea hemiformals & $\mathrm{HF} 2-m n$ & $1 . . n$ & 2 & 1 & 4 \\
\hline 1,1-Dimethylol urea hemiformals & $\mathrm{HF} 3-0 n$ & $2 . . n$ & 2 & 1 & 3 \\
\hline Trimethylol urea hemiformals & $\mathrm{HF} 4-0 n p$ & $2 . . n$ & 2 & 1 & 4 \\
\hline Trimethylol urea hemiformals & $\mathrm{HF} 4-m n 0$ & $2 . . n$ & 2 & 1 & 4 \\
\hline 1-Ureidomethyl urea, Methylene diurea & $\mathrm{MDU}$ & 2 & 4 & 2 & 1 \\
\hline 1-Ureidomethyl ureas, Methylene diureas & $\mathrm{MDUs}^{-}$ & $3 . . n$ & 4 & 2 & 2 \\
\hline Methoxymethylene diureas & $\mathrm{Ether}^{-}$ & $2 . . n$ & 4 & 2 & 2 \\
\hline Methylene glycol & $\mathrm{MG}_{1}$ & 1 & 1 & 0 & 1 \\
\hline Dimethylene glycol & $\mathrm{MG}_{2}$ & 1 & 2 & 0 & 2 \\
\hline Trimethylene glycol & $\mathrm{MG}_{3}$ & 2 & $2+1$ & 0 & 3 \\
\hline
\end{tabular}




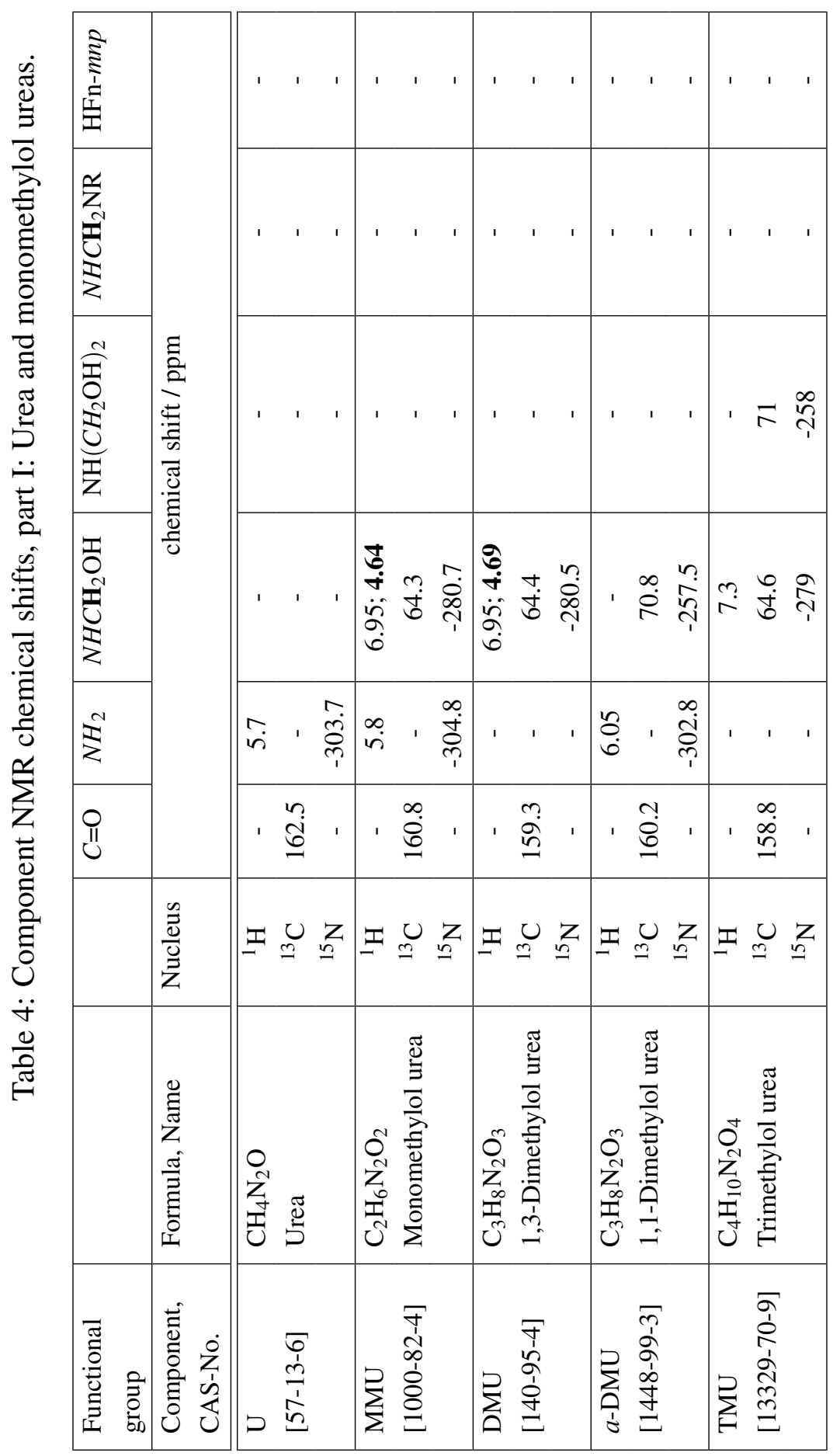




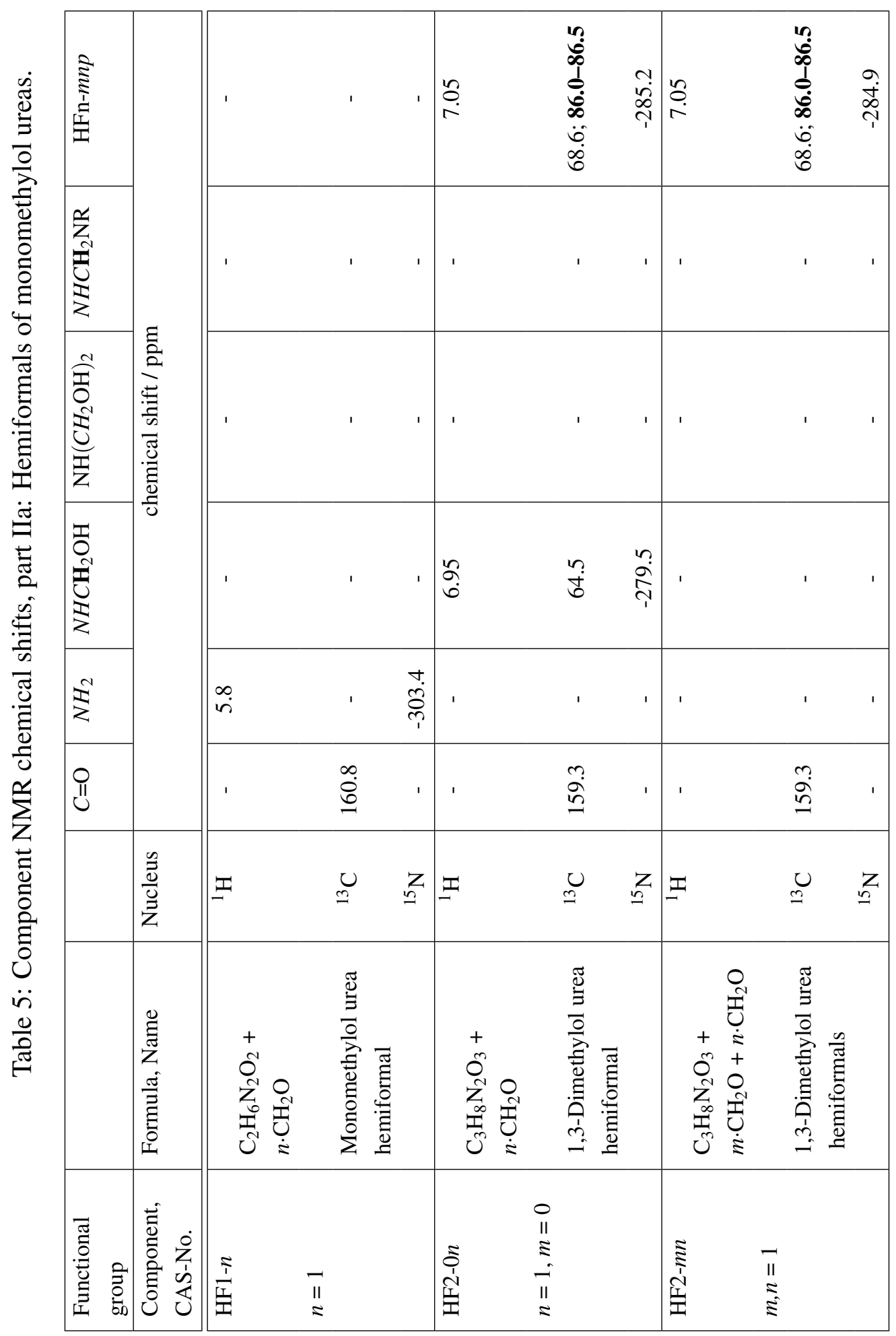




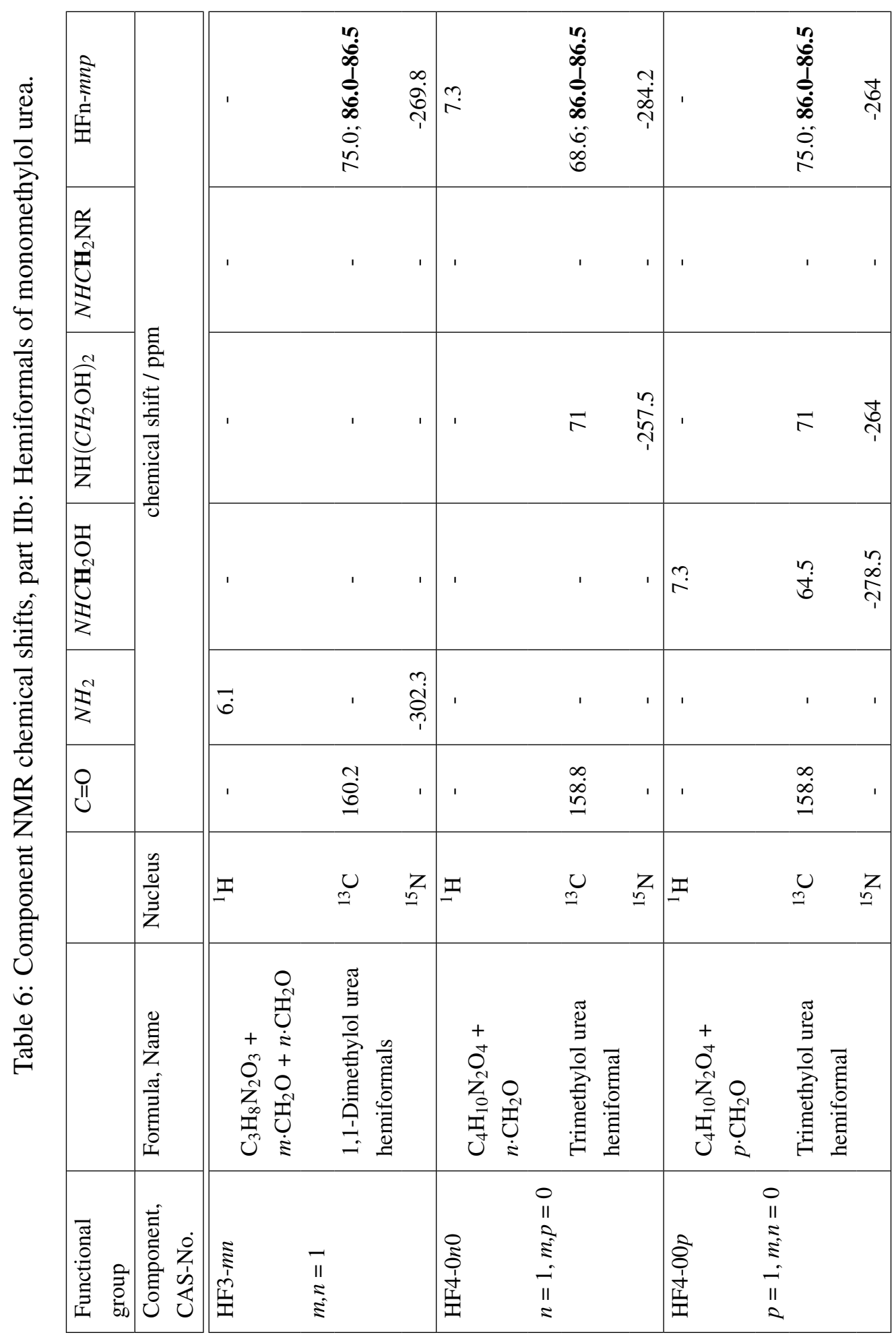




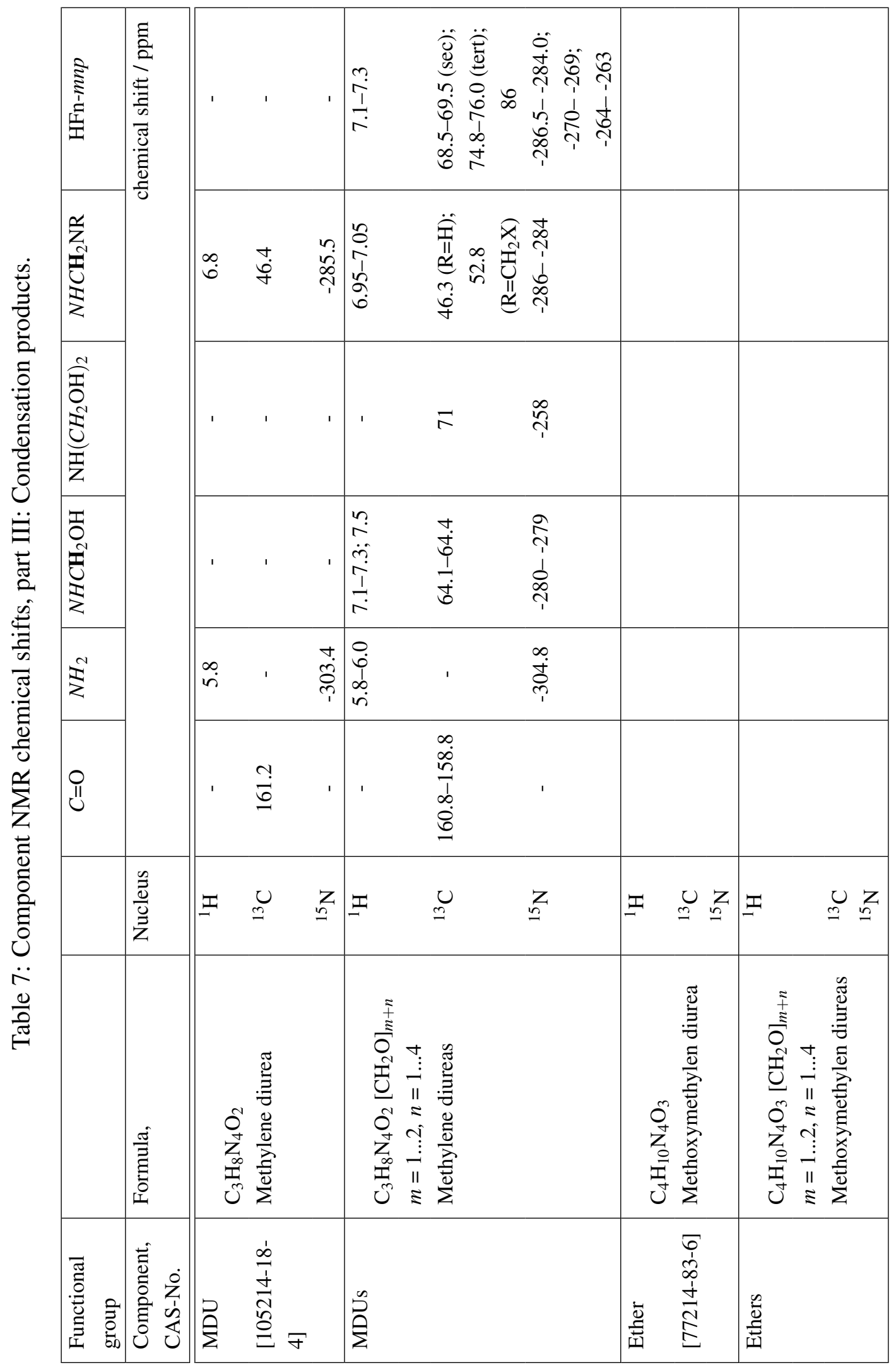




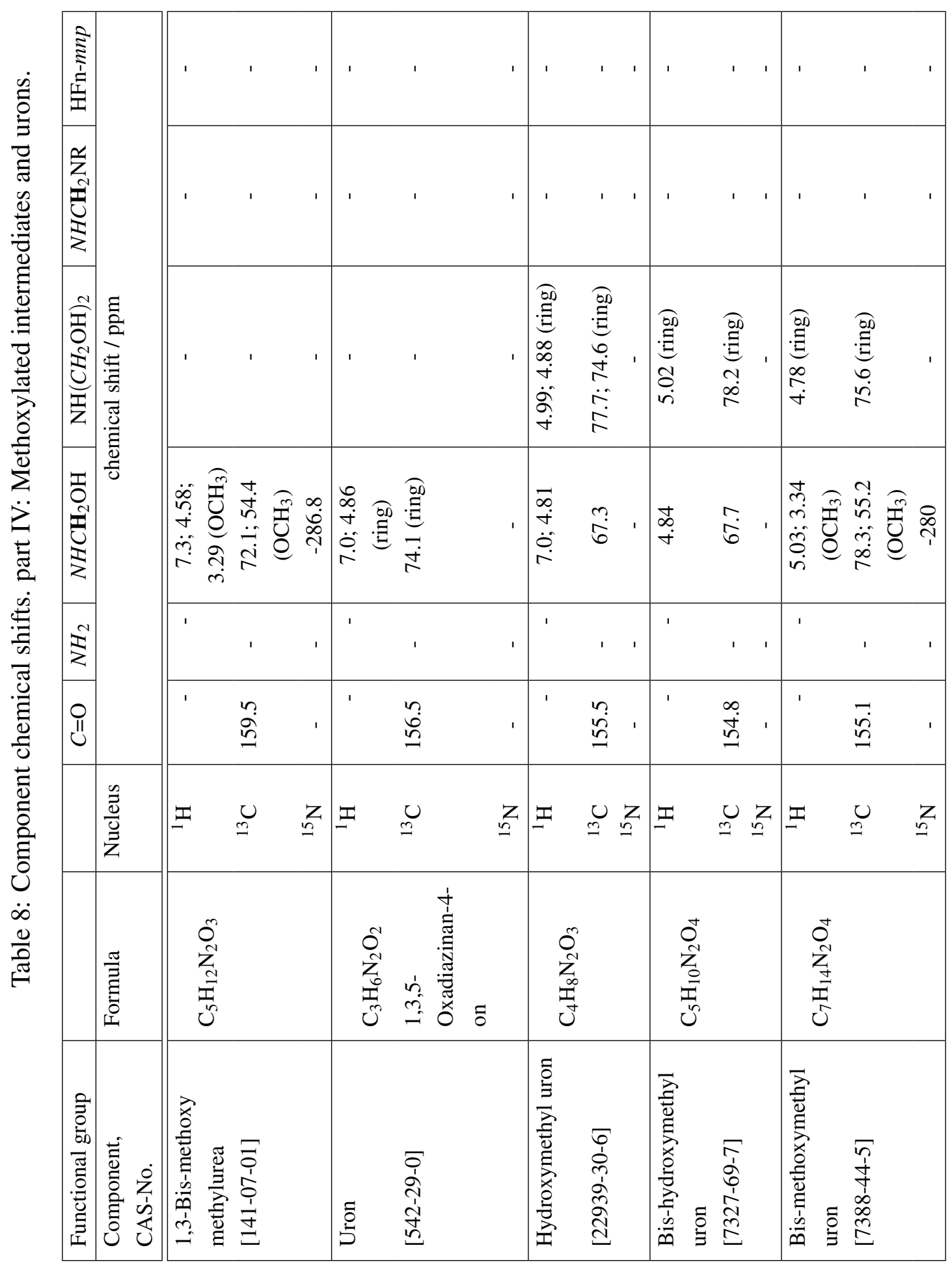




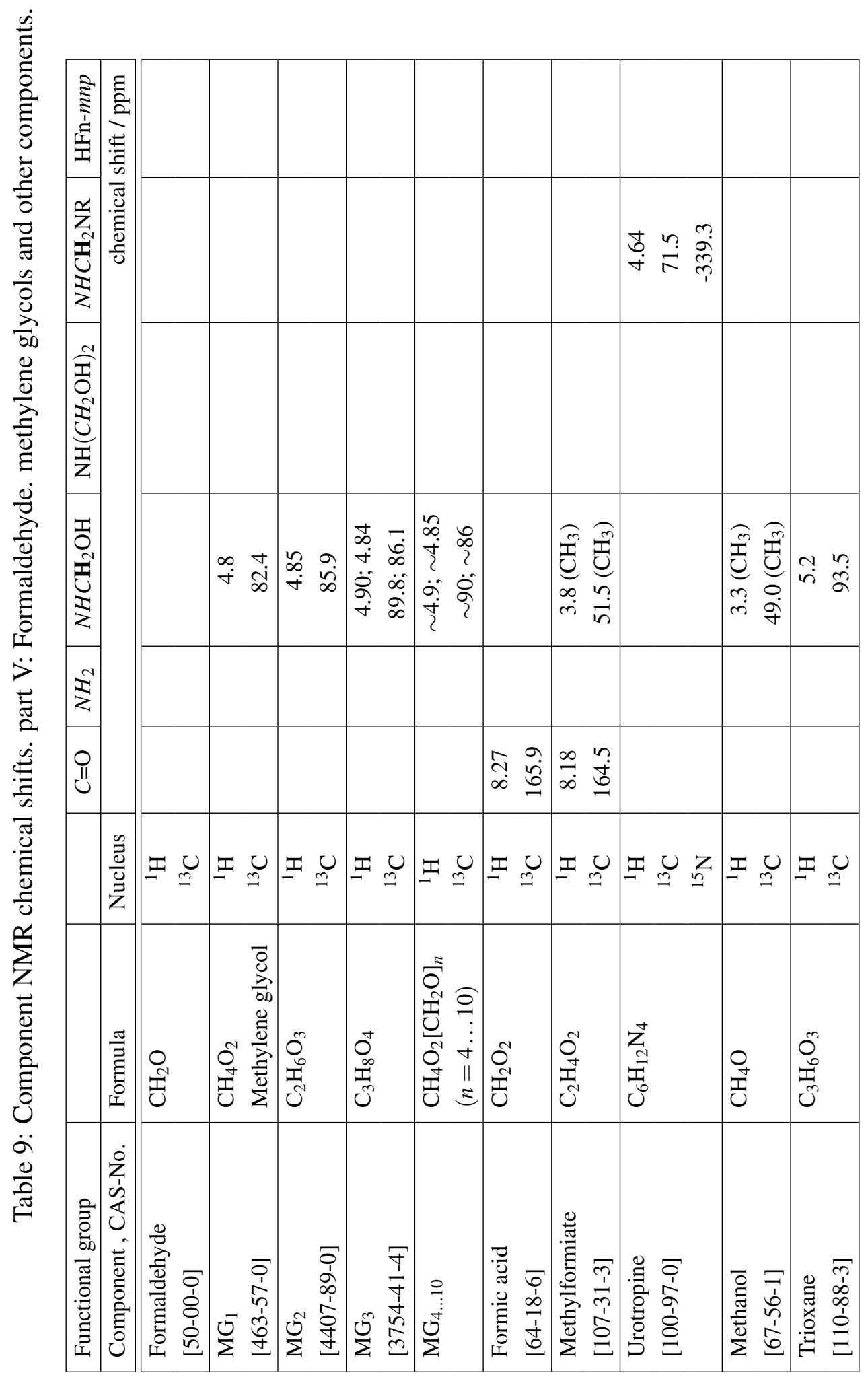


Table 10: Changes in NMR chemical shifts upon addition of formaldehyde (see Figure 15).

\begin{tabular}{|l|c|c|c|c|c|c|}
\hline Nucleus/Group & ${ }^{15} \mathrm{~N}$ (direct) & ${ }^{15} \mathrm{~N}$ (ind.) & ${ }^{13} \mathrm{C}\left(\mathrm{CH}_{2}\right)$ & ${ }^{13} \mathrm{C}(\mathrm{C}=\mathrm{O})$ & ${ }^{1} \mathrm{H}$ (direct) & ${ }^{1} \mathrm{H}$ (ind.) \\
\hline Chemical shift & \multicolumn{7}{|c|}{$\mathbf{~ p p m}$} \\
\hline \hline $\mathrm{NH}_{2} \rightarrow \mathrm{NH}\left(\mathrm{CH}_{2} \mathrm{OH}\right)$ & 24 & 0.6 (tert.: -0.4) & - & -1.5 & 1.3 & 0.06 \\
\hline $\begin{array}{l}\mathrm{NH}\left(\mathrm{CH}_{2} \mathrm{OH}\right) \rightarrow \\
\mathrm{N}\left(\mathrm{CH}_{2} \mathrm{OH}\right)_{2}\end{array}$ & 24 & 0.6 & 7 & -0.5 & - & 0.3 \\
\hline $\begin{array}{l}\mathrm{NH}\left(\mathrm{CH}_{2} \mathrm{OH}\right) \rightarrow \\
\mathrm{HF} 1-n ; \mathrm{HF} 2-0 n\end{array}$ & -6 & 0.4 & 4 & $<0.1$ & 0.075 & 0.075 \\
\hline $\begin{array}{l}\mathrm{N}\left(\mathrm{CH}_{2} \mathrm{OH}\right)_{2} \rightarrow \\
\mathrm{HF} 3-0 n ; \mathrm{HF} 4-0 n p\end{array}$ & -6 & 0.4 & 4 & $<0.1$ & - & n.a. \\
\hline $\begin{array}{l}\mathrm{HF} 3-0 n ; \mathrm{HF} 4-0 n p \rightarrow \\
\mathrm{HF} 3-m n ; \mathrm{HF} 4-m n p\end{array}$ & -6 & 0.4 & 4 & $<0.1$ & - & n.a. \\
\hline $\begin{array}{l}\mathrm{HF} 1-n ; \mathrm{HF} 2-0 n \rightarrow \\
\mathrm{HF} 3-0 n ; \mathrm{HF} 4-0 n p\end{array}$ & 24 & 0.6 & 6 & -0.5 & - & 0.3 \\
\hline
\end{tabular}


Table 11: Distribution of urea to different compounds described by pseudo mole fractions $\hat{x}_{i, \mathrm{UF}}$ based on the amount of urea at the start of the reaction $n_{0, \text { Urea }}$.

\begin{tabular}{|c|c|c|c|c|c|c|c|}
\hline \multicolumn{8}{|l|}{ Component } \\
\hline & \multicolumn{3}{|c|}{ pH 7.5} & \multicolumn{4}{|c|}{ pH 8.5} \\
\hline Sample Nr. & 1 & 2 & 3 & 4 & 5 & 6 & 7 \\
\hline \multirow[t]{2}{*}{ FA/U-ratio } & 1 & 2 & 4 & 1 & 1 & 2 & 4 \\
\hline & \multicolumn{7}{|c|}{$\hat{x}_{i, \mathrm{UF}} / \mathbf{m o l} \cdot \mathbf{m o l}^{-1}$} \\
\hline $\mathrm{U}$ & 0.253 & 0.027 & - & 0.270 & 0.268 & 0.036 & - \\
\hline MMU & 0.420 & 0.224 & 0.052 & 0.450 & 0.447 & 0.277 & 0.060 \\
\hline $\mathrm{DMU}$ & 0.150 & 0.344 & 0.314 & 0.177 & 0.173 & 0.435 & 0.296 \\
\hline$a$-DMU & 0.015 & 0.034 & 0.027 & 0.014 & 0.020 & 0.041 & 0.027 \\
\hline TMU & - & 0.092 & 0.247 & - & - & 0.086 & 0.231 \\
\hline HF1- $n$ & 0.035 & 0.059 & - & 0.022 & 0.024 & 0.045 & 0.006 \\
\hline HF2-0n & 0.055 & 0.114 & 0.162 & 0.040 & 0.044 & 0.063 & 0.187 \\
\hline HF2-mn & - & 0.018 & 0.048 & - & - & 0.011 & 0.045 \\
\hline HF4-mn0 & - & 0.018 & 0.091 & - & - & - & 0.102 \\
\hline HF4-0np & - & 0.019 & 0.059 & - & - & - & 0.046 \\
\hline \multirow[t]{2}{*}{ MDUs } & 0.036 & 0.026 & - & 0.013 & 0.012 & 0.003 & - \\
\hline & \multicolumn{7}{|c|}{$\hat{x}_{i, \mathrm{FA}} / \mathbf{m o l} \cdot \mathbf{m o l}^{-1}$} \\
\hline $\mathrm{MG}_{1}$ & 0.017 & 0.045 & 0.132 & 0.022 & 0.033 & 0.045 & 0.131 \\
\hline $\mathrm{MG}_{2}$ & - & 0.010 & 0.041 & - & - & 0.013 & 0.041 \\
\hline $\mathrm{MG}_{n}$ & - & 0.004 & 0.011 & - & - & 0.004 & 0.010 \\
\hline \multirow[t]{2}{*}{ Total $\mathrm{MG}_{n}$} & 0.017 & 0.059 & 0.184 & 0.022 & 0.033 & 0.062 & 0.182 \\
\hline & \multicolumn{7}{|c|}{ 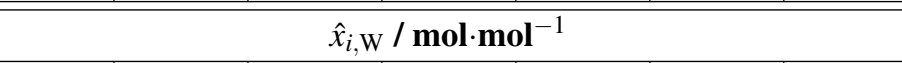 } \\
\hline Water from condensation & 0.002 & 0.002 & - & 0.001 & 0.001 & - & - \\
\hline Water bound in $\mathrm{MG}_{n}$ & -0.001 & -0.005 & -0.006 & -0.002 & -0.002 & -0.006 & -0.006 \\
\hline Initial water (FA-solution + buffer) & 0.999 & 1.003 & 1.006 & 1.001 & 1.001 & 1.005 & 1.006 \\
\hline Total water & 1.0 & 1.0 & 1.0 & 1.0 & 1.0 & 1.0 & 1.0 \\
\hline
\end{tabular}


Table 12: Composition of reaction mixtures given in mole fractions $x_{i}$.

\begin{tabular}{|c|c|c|c|c|c|c|c|}
\hline \multicolumn{8}{|l|}{ Component } \\
\hline & \multicolumn{3}{|c|}{ pH 7.5} & \multicolumn{4}{|c|}{ pH 8.5} \\
\hline Sample Nr. & 1 & 2 & 3 & 4 & 5 & 6 & 7 \\
\hline \multirow{2}{*}{ FA/U-ratio } & 1 & 2 & 4 & 1 & 1 & 2 & 4 \\
\hline & \multicolumn{7}{|c|}{$x_{i} / \mathbf{m o l} \cdot \mathbf{m o l}^{-1}$} \\
\hline $\mathrm{U}$ & 0.01597 & 0.00222 & - & 0.01705 & 0.01692 & 0.00291 & - \\
\hline MMU & 0.02647 & 0.01827 & 0.00169 & 0.02837 & 0.02821 & 0.02259 & 0.00195 \\
\hline DMU & 0.00943 & 0.02805 & 0.01024 & 0.01116 & 0.01088 & 0.03544 & 0.00964 \\
\hline$a$-DMU & 0.00097 & 0.00274 & 0.00087 & 0.00089 & 0.00124 & 0.00335 & 0.00088 \\
\hline TMU & - & 0.00747 & 0.00805 & - & - & 0.00698 & 0.00753 \\
\hline HF1- $n$ & 0.00221 & 0.00478 & - & 0.00136 & 0.00149 & 0.00365 & 0.00021 \\
\hline HF2-0n & 0.00349 & 0.00928 & 0.00527 & 0.00252 & 0.00277 & 0.00513 & 0.00608 \\
\hline HF2-mn & - & 0.00143 & 0.00156 & - & - & 0.00090 & 0.00146 \\
\hline HF4-mn0 & - & 0.00146 & 0.00297 & - & - & - & 0.00334 \\
\hline HF4-0np & - & 0.00155 & 0.00194 & - & - & - & 0.00149 \\
\hline MDUs & 0.00226 & 0.00212 & - & 0.00085 & 0.00077 & 0.00027 & - \\
\hline $\mathrm{MG}_{1}$ & 0.00109 & 0.00366 & 0.00431 & 0.00141 & 0.00205 & 0.00366 & 0.00428 \\
\hline $\mathrm{MG}_{2}$ & - & 0.00083 & 0.00133 & - & - & 0.00105 & 0.00135 \\
\hline $\mathrm{MG}_{n}$ & - & 0.00029 & 0.00036 & - & - & 0.00033 & 0.00031 \\
\hline $\begin{array}{l}\text { Water from condensation } \\
\text { (equal to } x_{\text {MDUs }} \text { ) }\end{array}$ & 0.00226 & 0.00212 & - & 0.00085 & 0.00077 & 0.00027 & - \\
\hline Water (other) & 0.93812 & 0.91586 & 0.96141 & 0.93639 & 0.93568 & 0.91375 & 0.96147 \\
\hline Total & 1.0 & 1.0 & 1.0 & 1.0 & 1.0 & 1.0 & 1.0 \\
\hline \multicolumn{8}{|l|}{$\begin{array}{l}\text { Additional figures } \\
\text { (subtotals of above balance, } \\
\text { but not part of it) }\end{array}$} \\
\hline $\begin{array}{l}\text { Total UF-intermediates } \\
\text { (sum of above) }\end{array}$ & 0.06079 & 0.07937 & 0.03259 & 0.06220 & 0.06227 & 0.08122 & 0.03259 \\
\hline $\begin{array}{l}\text { Total unreacted FA as } \mathrm{MG}_{n} \\
\left(\text { sum of } \mathrm{MG}_{n} \text { ) }\right.\end{array}$ & 0.00109 & 0.00618 & 0.00805 & 0.00141 & 0.00205 & 0.00674 & 0.00791 \\
\hline $\begin{array}{l}\text { Total FA bound to } \\
\text { UF-intermediates }\end{array}$ & 0.05970 & 0.15257 & 0.12229 & 0.06078 & 0.06022 & 0.15571 & 0.12243 \\
\hline Ratio FA bound/unbound & 55 & 25 & 15 & 43 & 29 & 23 & 15 \\
\hline $\begin{array}{l}\text { Total FA (unreacted + } \\
\text { UF-bound) }\end{array}$ & 0.06079 & 0.15874 & 0.13035 & 0.06220 & 0.06227 & 0.16244 & 0.13035 \\
\hline Subtotal FA bound in HFn & 0.01487 & 0.05516 & 0.04165 & 0.01027 & 0.01128 & 0.02629 & 0.04383 \\
\hline Ratio FA HF/MG ${ }_{n}$ & 13.7 & 8.9 & 5.2 & 7.3 & 5.5 & 3.9 & 5.5 \\
\hline Water bound in $\mathrm{MG}_{n}$ & -0.00109 & -0.00477 & -0.00600 & -0.00141 & -0.00205 & -0.00503 & -0.00594 \\
\hline
\end{tabular}




\section{Appendix}

\section{Synthesis of single components}

Monomethylol urea, MMU Synthesis, workup and purification are carried out following the procedure of de Jong and de Jonge ${ }^{16}$, a yield of $26.6 \%$ with regard to urea was obtained. $540 \mathrm{~g}$ urea were dissolved in $375 \mathrm{~g}$ of distilled water and cooled to $5^{\circ} \mathrm{C}$. The $\mathrm{pH}$-value was adjusted to 8.0 using an automated $\mathrm{pH}$ control system dosing aqueous solutions of sodium hydroxide and formic acid to keep the $\mathrm{pH}$-value constant. Over the course of $1 \mathrm{~h}, 676 \mathrm{~g}$ of an aqueous solution of formaldehyde $\left(x_{0, \mathrm{FA}}=0.3 \mathrm{~g} / \mathrm{g}\right)$ were added while keeping the temperature below $25^{\circ} \mathrm{C}$. Workup and purification was done as described by de Jong and de Jonge. $221 \mathrm{~g}$ of monomethylol urea with purity in excess of $90 \%$ were obtained, corresponding to a yield of $26.6 \%$ with regard to urea.

TLC: $\mathrm{R}_{f}=0,30$ (green spot); ${ }^{1} \mathrm{H}$ NMR $\left(\mathrm{H}_{2} \mathrm{O}\right): \delta=7,1\left(\mathrm{bt}, J=7,0 \mathrm{~Hz}, 1 \mathrm{H}, \mathrm{OCH}_{2} \mathrm{NH}\right) ; 5,9(2 \mathrm{H}$, $\left.\mathrm{NH}_{2}\right) ; 4,64\left(\mathrm{~d}, J=7,0 \mathrm{~Hz}, 2 \mathrm{H}, \mathrm{OCH}_{2} \mathrm{NH}\right) .{ }^{13} \mathrm{C} \mathrm{NMR}\left(\mathrm{H}_{2} \mathrm{O}\right): \delta=160,8(1 \mathrm{C}, C=\mathrm{O}) ; 64,3(1 \mathrm{C}$, $\left.\mathrm{CH}_{2}\right) .{ }^{15} \mathrm{~N} \mathrm{NMR}\left(\mathrm{H}_{2} \mathrm{O}\right): \delta_{\mathrm{CD}_{3} \mathrm{NO}_{2}}=-280,7\left(\mathrm{~d},{ }^{1} J_{\mathrm{N}, \mathrm{H}}=|91,5| \mathrm{Hz}, \mathrm{OCH}_{2} N \mathrm{H},\right) ;-304,8\left(\mathrm{t},{ }^{1} J_{\mathrm{N}, \mathrm{H}}=\right.$ $\left.|89,2| \mathrm{Hz}, \mathrm{NH}_{2}\right)$. Melting point: $110^{\circ} \mathrm{C}$.

1,3-Bishydroxymethyl urea (Dimethylol urea), DMU $400 \mathrm{~g}$ of an aqueous formaldehyde solution $\left(x_{0, \mathrm{FA}}=0.3 \mathrm{~g} / \mathrm{g}\right)$ were adjusted to $5^{\circ} \mathrm{C}$ and $\mathrm{pH}$-value 8.0. Then $120 \mathrm{~g}$ of solid urea was added sufficiently slowly to keep the temperature below $25^{\circ} \mathrm{C}$. The $\mathrm{pH}$-value was kept at 8.0 by means of the automatic $\mathrm{pH}$ control system mentioned above. After 2 hours of stirring, the mixture was stored at $0^{\circ} \mathrm{C}$ for 16 hours. Then water was evaporated under vacuum until the volume was reduced to $50 \%$ while keeping the temperature below $50^{\circ} \mathrm{C}$. The precipitate was removed and washed once with ethanol, then once with diethylether. A second fraction of solid was obtained by storing the mother liquors at $0^{\circ} \mathrm{C}$ for 24 hours. This was washed in the same way. Both fractions were combined and recrystallized from 1.5 liters of a mixture of ethanol and diethylether at a ratio of 3:2 with $1 \mathrm{~g}$ of $\mathrm{K}_{3} \mathrm{PO}_{4}$ added as a buffer. $107.8 \mathrm{~g}$ of the target component with $95 \%$ purity were obtained. This represents a yield of $43 \%$ with regard to urea. 
TLC: $\mathrm{R}_{f}=0,21$ (yellow spot); ${ }^{1} \mathrm{H}$ NMR $\left(\mathrm{D}_{2} \mathrm{O}\right): \delta=7,1\left(\mathrm{bt}, J=6,8 \mathrm{~Hz}, 2 \mathrm{H}, \mathrm{OCH}_{2} \mathrm{~N} H\right) ; 4,69(\mathrm{~d}, J$ $\left.=6,8 \mathrm{~Hz}, 4 \mathrm{H}, \mathrm{OCH}_{2} \mathrm{NH}\right) .{ }^{13} \mathrm{C} \mathrm{NMR}\left(\mathrm{D}_{2} \mathrm{O}\right): \delta=159,3(1 \mathrm{C}, \mathrm{C}=\mathrm{O}) ; 64,2\left(2 \mathrm{C}, \mathrm{CH}_{2}\right) \cdot{ }^{15} \mathrm{~N}$ NMR $\left(\mathrm{H}_{2} \mathrm{O}\right): \delta_{\mathrm{CD}_{3} \mathrm{NO}_{2}}=-280,5\left(\mathrm{OCH}_{2} \mathrm{NH}\right)$. Melting point: $114^{\circ} \mathrm{C}$.

1-Ureidomethyl urea (Methylene diurea), MDU 1-Ureidomethyl urea was prepared from both industrial and ${ }^{15} \mathrm{~N}$-labeled urea following Murray's approach ${ }^{95}$. The yield was $65 \%$ with regard to formaldehyde at $95 \%$ purity at $50 \mathrm{~g}$ scale. Labeled material was prepared at $0.5 \mathrm{~g}$ scale with a yield of $30 \%$.

TLC: $\mathrm{R}_{f}=0,30$ (blue spot); ${ }^{1} \mathrm{H}$ NMR $\left(\mathrm{H}_{2} \mathrm{O}\right): \delta=6,8$ (bt, $\left.J=6,3 \mathrm{~Hz}, 2 \mathrm{H}, \mathrm{NHCH}_{2} \mathrm{NH}\right) ; 5,8(\mathrm{~s}, 4 \mathrm{H}$, $\left.\mathrm{NH}_{2}\right) ; 4,43\left(\mathrm{t}, J=6,3 \mathrm{~Hz}, 4 \mathrm{H}, \mathrm{NHCH}_{2} \mathrm{NH}\right) .{ }^{13} \mathrm{C} \mathrm{NMR}\left(\mathrm{H}_{2} \mathrm{O}\right): \delta=161,2(2 \mathrm{C}, \mathrm{C}=\mathrm{O}) ; 46,4(1 \mathrm{C}$, $\left.\mathrm{NHCH}{ }_{2} \mathrm{NH}\right) .{ }^{15} \mathrm{~N} \mathrm{NMR}\left(\mathrm{H}_{2} \mathrm{O}\right): \delta_{\mathrm{CD}_{3} \mathrm{NO}_{2}}=-286\left(\mathrm{~d},{ }^{1} J_{\mathrm{N}, \mathrm{H}}=|90| \mathrm{Hz}, 2 \mathrm{~N}, N \mathrm{HCH}_{2} N \mathrm{H}\right) ;-303(\mathrm{t}$, ${ }^{1} J_{\mathrm{N}, \mathrm{H}}=|86| \mathrm{Hz}, 2 \mathrm{~N}, N \mathrm{H}_{2}$ ). Melting point: $201^{\circ} \mathrm{C}$ (decomposition).

\section{1-Hydroxymethyl-3-(3-Hydroxymethylureidomethyl) urea (Bishydroxymethyl-methylene di-}

ureas), MDUs To a solution of $3 \mathrm{~g}$ of 1-ureidomethylurea in $100 \mathrm{ml}$ of water an aqueous solution of formaldehyde $\left(x_{0, \mathrm{FA}}=0.3 \mathrm{~g} / \mathrm{g}\right)$ was slowly added at $60^{\circ} \mathrm{C}$. Both solutions were previously adjusted to $\mathrm{pH}$-value 9.0. The mixture was stirred for 20 minutes. The precipitate was filtered off, washed twice with water, once with diethylether and dried under vacuum. The precipitate was identified as consisting largely of 1-hydroxymethy-3-(3-hydroxymethylureidomethyl) urea by NMR spectroscopy. The yield was $31.6 \%$ with regard to 1-ureidomethyl urea.

TLC: $\mathrm{R}_{f}=0,21$ (green spot); ${ }^{1} \mathrm{H}$ NMR $\left(\mathrm{H}_{2} \mathrm{O}\right): \delta=7,0\left(2 \mathrm{H}, \mathrm{NHCH}_{2} \mathrm{OH}\right) ; 6,8\left(2 \mathrm{H}, \mathrm{NHCH}_{2} \mathrm{~N} H\right)$; $4,8\left(4 \mathrm{H}, \mathrm{NHCH}_{2} \mathrm{OH}\right) ; 4,4\left(2 \mathrm{H}, \mathrm{NHCH}_{2} \mathrm{NH}\right) .{ }^{13} \mathrm{C} \mathrm{NMR}\left(\mathrm{H}_{2} \mathrm{O}\right): \delta=159,5(2 \mathrm{C}, \mathrm{C}=\mathrm{O}) ; 64,2(2 \mathrm{C}$, $\left.\mathrm{NHCH} \mathrm{H}_{2} \mathrm{OH}\right) ; 46\left(1 \mathrm{C}, \mathrm{NHCH}_{2} \mathrm{NH}\right) .{ }^{15} \mathrm{~N} \mathrm{NMR}\left(\mathrm{H}_{2} \mathrm{O}\right): \delta_{\mathrm{CD}_{3} \mathrm{NO}_{2}}=-279\left(2 \mathrm{~N}, N \mathrm{HCH}_{2} \mathrm{OH}\right) ;-286$ $\left(2 \mathrm{~N}, \mathrm{NHCH}_{2} \mathrm{NH}\right)$.

1,3-Bismethoxymethyl urea 1,3-Bismethoxymethyl urea was obtained following Kadowaki's approach $^{4}$ with a yield of $35.6 \%$ at $99 \%$ purity. 
TLC: $\mathrm{R}_{f}=0,70$ (yellow spot); ${ }^{1} \mathrm{H}$ NMR $\left(\mathrm{H}_{2} \mathrm{O}\right): \delta=7,3$ (bt, $J=6,8 \mathrm{~Hz}, 2 \mathrm{H}, \mathrm{CH}_{3} \mathrm{OCH}_{2} \mathrm{NH}$ ); 4,58 (d, $\left.J=6,8 \mathrm{~Hz}, 4 \mathrm{H}, \mathrm{CH}_{3} \mathrm{OCH}_{2} \mathrm{NH}\right) ; 3,29$ (s, $\left.6 \mathrm{H}, \mathrm{CH}_{3} \mathrm{OCH}_{2} \mathrm{NH}\right) .{ }^{13} \mathrm{C} \mathrm{NMR}\left(\mathrm{H}_{2} \mathrm{O}\right): \delta=159,5(1 \mathrm{C}$, $C=\mathrm{O}) ; 72,1\left(2 \mathrm{C}, \mathrm{CH}_{3} \mathrm{OCH}_{2} \mathrm{NH}\right) ; 54,4\left(2 \mathrm{C}, \mathrm{CH}_{3} \mathrm{OCH}_{2} \mathrm{NH}\right) .{ }^{15} \mathrm{~N} \mathrm{NMR}\left(\mathrm{H}_{2} \mathrm{O}\right): \delta_{\mathrm{CD}_{3} \mathrm{NO}_{2}}=-286,8$ $\left(\mathrm{d},{ }^{1} J_{\mathrm{N}, \mathrm{H}}=|91,6| \mathrm{Hz}, \mathrm{CH}_{3} \mathrm{OCH}_{2} \mathrm{NH}\right) . \mathrm{MS}(\mathrm{EI}): \mathrm{m} / \mathrm{z}=133,1\left(\mathrm{M}^{+}-\mathrm{CH}_{3}\right) ; 117,1\left(\mathrm{M}^{+}-\mathrm{OCH}_{3}\right)$; $101,1\left(\mathrm{M}^{+}-\mathrm{OCH}_{3}-\mathrm{CH}_{3}\right) ; 85,0\left(\mathrm{M}^{+}-2 \mathrm{OCH}_{3}\right) ; 60,1\left(\mathrm{M}^{+}-2 \mathrm{CH}_{2} \mathrm{OCH}_{3}\right)$. Melting point: $96^{\circ} \mathrm{C}$.

3,5-Bismethoxymethyl-1,3,5-Oxadiazinan-4-on (1,3-Bismethoxymethyl uron) Synthesis was done as reported by Kadowaki ${ }^{4}$ and Paquin ${ }^{96}$. To $400 \mathrm{~g}$ aqueous formaldehyde solution $\left(x_{0, \mathrm{FA}}=\right.$ $0.3 \mathrm{~g} / \mathrm{g}) 15 \mathrm{~g} \mathrm{Ba}(\mathrm{OH})_{2}$ and $60.1 \mathrm{~g}$ urea were added. The mixture was refluxed for 10 minutes while stirring. Then it was reduced under vacuum until most of the water evaporated while keeping the temperature below $40^{\circ} \mathrm{C}$. The remaining viscous liquid was taken up with 1 litre of methanol. After addition of $40 \mathrm{ml}$ hydrochloric acid $\left(x_{m}=0.37 \mathrm{~g} / \mathrm{g}\right)$ the mixture was stirred for 12 hours at ambient temperature. After neutralization with $\mathrm{Ba}(\mathrm{OH})_{2}$ the methanol was removed under vacuum. The residue was taken up with 0.5 liters of chloroform and filtered to remove inorganic salts. The chloroform was evaporated. The residue was taken up with diethylether. 1,3-Bismethoxymethylurea was filtered off as precipitate. After removal of the solvents the mother liquors were subjected to vacuum distillation. Three fractions were obtained between $110-115^{\circ} \mathrm{C}$ at $1.5-1.7 \mathrm{mbar}$. The oily liquid was identified as 3,5-bismethoxymethyl-1,3,5-oxadiazinan-4-on by NMR spectroscopy. The yield was $4 \mathrm{~g}$, representing $2 \%$ yield with regard to urea. The high yield reported by Kadowaki could not be reproduced here. The low selectivity of the uron formation may be explained by competition of the ring condensation with the formation of the methyl ether.

TLC: $\mathrm{R}_{f}=0,79$ (yellow spot); ${ }^{1} \mathrm{H}$ NMR $\left(\mathrm{D}_{2} \mathrm{O}\right): \delta=5,03$ (s, 4H, $\left.\mathrm{NCH}_{2} \mathrm{OCH}_{3}\right) ; 4,78(\mathrm{~s}, 4 \mathrm{H}$, $\left.\mathrm{NCH}_{2} \mathrm{OCH} \mathrm{H}_{2} \mathrm{~N}\right) ; 3,34\left(\mathrm{~s}, 6 \mathrm{H}, \mathrm{OCH}_{3}\right) \cdot{ }^{13} \mathrm{C} \mathrm{NMR}\left(\mathrm{D}_{2} \mathrm{O}\right): \delta=155,1(1 \mathrm{C}, \mathrm{C}=\mathrm{O}) ; 78,3(2 \mathrm{C}$, $\left.\mathrm{NCH}_{2} \mathrm{OCH}_{3}\right) ; 75,6\left(2 \mathrm{C}, \mathrm{NCH}_{2} \mathrm{OCH} \mathrm{H}_{2} \mathrm{~N}\right) ; 55,2\left(2 \mathrm{C}, \mathrm{OCH}_{3}\right) .{ }^{15} \mathrm{~N} \mathrm{NMR}\left(\mathrm{H}_{2} \mathrm{O}\right): \delta_{\mathrm{CD}_{3} \mathrm{NO}_{2}}=-280,0$ $\left(N_{2} \mathrm{OCH}_{2} N\right)$. MS (EI): m/z = 190,1 $\left(\mathrm{M}^{+}\right) ; 175,1\left(\mathrm{M}^{+}-\mathrm{CH}_{3}\right) ; 159,1\left(\mathrm{M}^{+}-\mathrm{OCH}_{3}\right) ; 143,1\left(\mathrm{M}^{+}\right.$ - $\left.\mathrm{CH}_{2} \mathrm{OCH}_{3}\right) ; 128,1\left(\mathrm{M}^{+}-2 \mathrm{OCH}_{3}\right) ; 114,1\left(\mathrm{M}^{+}-2 \mathrm{CH}_{2} \mathrm{OCH}_{3}\right)$. 
Mixture of 1,3,5-Oxadiazinan-4-ones, Urons Following Beachem's ${ }^{77}$ procedure, a solution of $1 \mathrm{~g}$ 3,5-bismethoxymethyl-1,3,5-oxadiazinan-4-on in $300 \mathrm{ml}$ of water was refluxed with $2.95 \mathrm{~g}$ of dimedone (5,5-dimethylcyclohexane-1,3-dion) for 20 minutes. After cooling down to room temperature the precipitate was removed by filtration. The mother liquors were reduced to approximately $10 \%$ of the original volume while maintaining the temperature below $50^{\circ} \mathrm{C}$ and filtered again to remove all solids. The liquors were reduced to dryness and recrystallized from acetonitrile. The obtained crystals were identified as 1,3,5-oxadiazinan-4-on, the liquors contained a mixture of 3-hydroxymethyl-1,3,5-oxadiazinan-4-on and 3,5-bishydroxymethyl-1,3,5-oxadiazinan-4-on. No attempt was made to further separate the latter two components, as this two component mixture was sufficient for characterization by NMR spectroscopy.

1,3,5-Oxadiazinan-4-on, Uron Prepared as described above.

TLC: $\mathrm{R}_{f}=0,46$ (yellow spot). ${ }^{1} \mathrm{H}$ NMR ( $\left.\mathrm{D}_{2} \mathrm{O}\right): \delta=7$ (s, $\left.2 \mathrm{H}, \mathrm{NHCH}_{2} \mathrm{OCH}_{2} \mathrm{~N} H\right) ; 4,86(\mathrm{~s}, 4 \mathrm{H}$, $\left.\mathrm{NHCH}_{2} \mathrm{OCH}_{2} \mathrm{NH}\right) .{ }^{13} \mathrm{C} \mathrm{NMR}\left(\mathrm{D}_{2} \mathrm{O}\right): \delta=156,5(1 \mathrm{C}, \mathrm{C}=\mathrm{O}) ; 74,1\left(2 \mathrm{C}, \mathrm{NHCH}_{2} \mathrm{OCH}_{2} \mathrm{NH}\right)$.

3-Hydroxymethyl-1,3,5-Oxadiazinan-4-on, Hydroxymethyl uron Prepared as described above.

${ }^{1} \mathrm{H}$ NMR $\left(\mathrm{D}_{2} \mathrm{O}\right): \delta=7\left(\mathrm{~s}, 1 \mathrm{H}, \mathrm{HOCH}_{2} \mathrm{NCH}_{2} \mathrm{OCH}_{2} \mathrm{NH}\right) ; 4,99\left(\mathrm{~s}, 2 \mathrm{H}, \mathrm{HOCH}_{2} \mathrm{NCH}_{2} \mathrm{OCH}_{2} \mathrm{NH}\right) ;$ 4,88 (s, $2 \mathrm{H}, \mathrm{HOCH}_{2} \mathrm{NCH}_{2} \mathrm{OCH} \mathrm{H}_{2} \mathrm{NH}$ ); 4,81 (s, $\left.2 \mathrm{H}, \mathrm{HOCH}_{2} \mathrm{NCH}_{2} \mathrm{OCH}_{2} \mathrm{NH}\right) \cdot{ }^{13} \mathrm{C} \mathrm{NMR}\left(\mathrm{D}_{2} \mathrm{O}\right)$ : $\delta=155,5(1 \mathrm{C}, C=\mathrm{O}) ; 77,7\left(1 \mathrm{C}, \mathrm{HOCH}_{2} \mathrm{NCH}_{2} \mathrm{OCH}_{2} \mathrm{NH}\right) ; 74,6\left(1 \mathrm{C}, \mathrm{HOCH}_{2} \mathrm{NCH}_{2} \mathrm{OCH} \mathrm{H}_{2} \mathrm{NH}\right)$; $67,3\left(1 \mathrm{C}, \mathrm{HOCH}_{2} \mathrm{NCH}_{2} \mathrm{OCH}_{2} \mathrm{NH}\right)$.

3,5-bis-Hydroxymethyl-1,3,5-Oxadiazinan-4-on, Bishydroxymethyl uron Prepared as described above.

${ }^{1} \mathrm{H}$ NMR $\left(\mathrm{D}_{2} \mathrm{O}\right): \delta=5,02\left(\mathrm{~s}, 4 \mathrm{H}, \mathrm{HOCH}_{2} \mathrm{NCH}_{2} \mathrm{OCH}_{2} \mathrm{NCH}_{2} \mathrm{OH}\right) ; 4,84$ (s, 4H, $\left.\mathrm{HOCH}_{2} \mathrm{NCH}_{2} \mathrm{OCH}_{2} \mathrm{NCH}_{2} \mathrm{OH}\right) .{ }^{13} \mathrm{C}$ NMR $\left(\mathrm{D}_{2} \mathrm{O}\right): \delta=154,8(1 \mathrm{C}, \mathrm{C}=\mathrm{O}) ; 78,2(2 \mathrm{C}$, $\left.\mathrm{HOCH}_{2} \mathrm{NCH}_{2} \mathrm{OCH}_{2} \mathrm{NCH}_{2} \mathrm{OH}\right) ; 67,7\left(2 \mathrm{C}, \mathrm{HOCH}_{2} \mathrm{NCH}_{2} \mathrm{OCH}_{2} \mathrm{NCH}_{2} \mathrm{OH}\right)$. 


\section{Supplementary Material}

\section{Thin film chromatography}

For thin film chromatography, polyester plates coated with silica gel 60 of the type SIL G/UV254, purchased from Macherey-Nagel (DÃGEren, Germany), were used. As mobile phase, a volumetric mixture of ethyl acetate, methanol and aqueous ammonia $\left(x_{m}=0.25 \mathrm{~g} / \mathrm{g}\right)$ in the ratio 79:30:1 was used. None of the analytes shows absorption in the UV-VIS region, so staining was required. The method described by Ludlam (57), employing exposure to a chlorine atmosphere followed by treatment with $o$-toluidine in glacial acetic acid, was used here. This method has the added benefit of staining components in different colors, depending on their chemistry. Urea and ureaformaldehyde derivatives with unsubstituted $\mathrm{NH}_{2}$-groups and no potential to release formaldehyde are stained blue. Derivatives with unsubstituted $\mathrm{NH}_{2}$-groups and the potential to release formaldehyde are stained green. Components with only substituted NHR-groups and the potential to release formaldehyde give a yellow stain. In the latter case, the time needed for the stain to fully develop gives an indication how easily formaldehyde is released from a specific component. Urons and methoxymethylated derivatives exhibit comparably slow development here (up to $24 \mathrm{~h}$ ), while unsubstituted ureas develop in seconds. 


\section{Recovery rate of the quantification of $1 \mathrm{D}-{ }^{15} \mathrm{~N}$ NMR spectra}

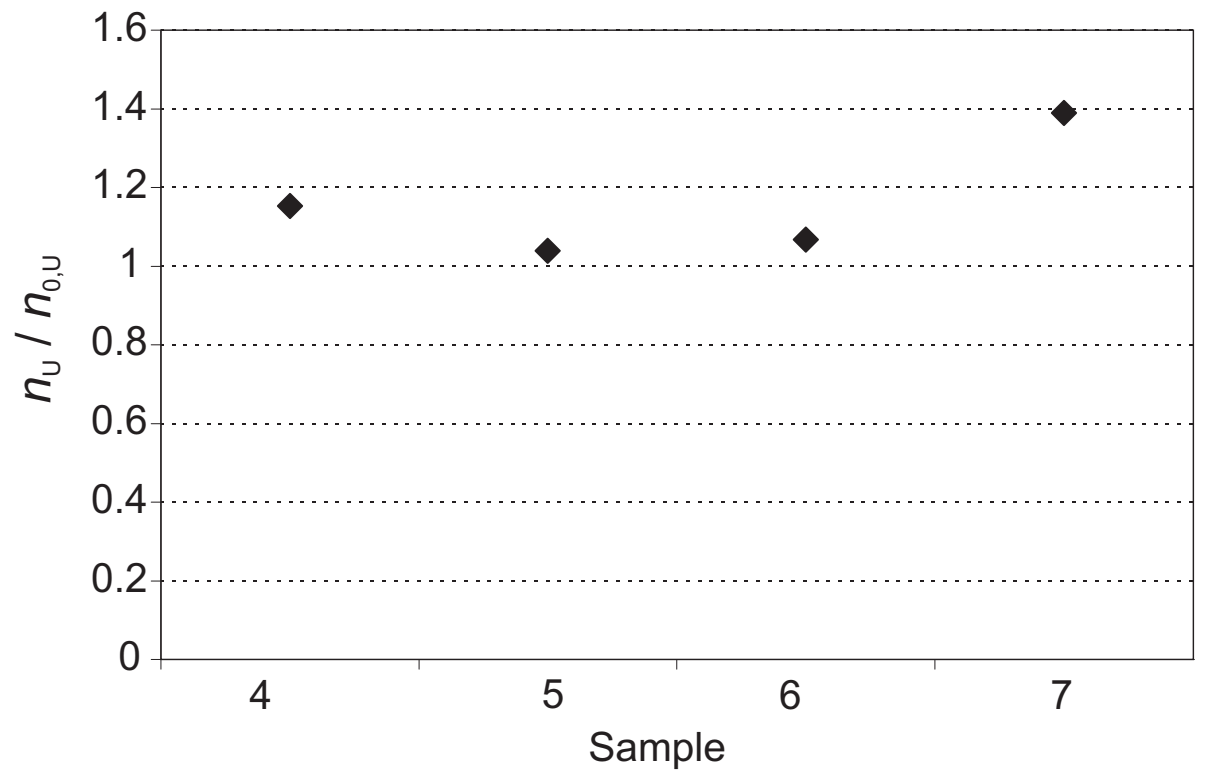

Abbildung 21: Recovery rate of the quantitative $1 \mathrm{D}^{15} \mathrm{~N}$ NMR analysis of samples 4 to 7 (pH-value 8.5). The ratio $n_{\mathrm{U}} / n_{0, \mathrm{U}}$ describes the theoretically expected vs. actual molar quantity of urea units in the sample. 